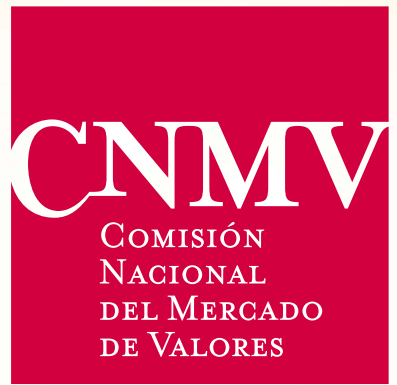

Comisión

NAGIONAL

DE VALORES
Financial education and savings and investment decisions: An analysis of the Survey of Financial Competences (ECF)

Anna Ispierto Maté Irma Martínez García Gloria Ruiz Suárez

Working paper

No. 75 



\section{Financial education and savings and investment decisions: An analysis of the Survey of Financial Competences (ECF)}

Anna Ispierto Maté ${ }^{1}$

Irma Martínez García ${ }^{1}$

Gloria Ruiz Suárez ${ }^{1}$

Working paper

No. 75

March 2021

1 Anna Ispierto, Irma Martínez and Gloria Ruiz belong to the Department of Research and Statistics of the CNMV's Directorate General for Strategic Policy and International Affairs. 
The CNMV publishes this Working Paper Series to spread research in order to contribute towards greater knowledge of the stock markets and their regulation.

The opinions in this Working Paper are the sole responsibility of the author and they do not necessarily coincide with those of the CNMV.

The CNMV distributes its reports and publications via the Internet at www.cnmv.es

(C) CNMV. The contents of this publication may be reproduced, subject to attribution.

ISSN (digital edition): 1988-2025

Layout: Cálamo y Cran 


\section{Table of contents}

Summary

Introduction

1 General and financial knowledge of the population

Relationship between the individual's profile and general and financial knowledge

3

Attitudes towards saving

4 Holding of financial products

Financial competences and saving and investment decisions

6

Conclusions 



\section{Summary}

This working document analyses and develops the information deriving from the Survey of Financial Competences from a dual perspective. Firstly, it presents an evaluation of the level of financial knowledge of the individuals in the sample, in comparison with a series of available socio-demographic and economic variables and, secondly, it seeks to establish the influence of financial knowledge on the decision to save and/or invest in a specific financial product, such as an investment fund or pension scheme. The Survey of Financial Competences was prepared jointly by the Bank of Spain and the CNMV, with the collaboration of the National Institute of Statistics, between 2016 and 2017 as part of the Financial Education Plan. The survey consists of around 200 questions $^{1}$ submitted to 8,554 individuals in relation to their knowledge of economic and financial concepts, their ability to save and their holding of financial products.

According to the data analysis, the average score obtained by the sample in the financial knowledge evaluation is 6 out of 10 , with $70 \%$ of individuals showing medium or high knowledge and $25 \%$ showing low or very low knowledge. The oldest age group shows the lowest general and financial knowledge. The knowledge of the younger age groups is observed to be higher, with very small differences between them. A higher proportion of men ( $82 \%$ compared to $71 \%$ of women) show a medium or higher level of financial knowledge and the higher the educational level attained by the individual, the greater their financial (and general) knowledge. The data also appear to indicate the importance of acquiring the early stages of financial education in learning.

There also appears to be a positive relationship between the individual's income level and their level of financial knowledge, although this relationship does not appear to be linear, in other words, the level of knowledge is relatively similar among lower-income groups and the same occurs for the higher-income groups. The greatest variation in knowledge is observed between the low-income and middle-income brackets. Analysis of the individual's attitude towards saving shows that respondents generally give very high importance to saving, although almost $40 \%$ of them state that they have not saved in the past year. People who save usually opt for a very small number of financial assets, in few cases more than two.

The empirical work carried out to contrast the role of an individual's financial knowledge in financial decision-making finds that these competences have a positive impact on the probability of acquiring investment funds and buying shares and (public or private) fixed income assets. The results obtained lead us to conclude that

1 Each individual was asked an average of 115 questions. 
there is a causal relationship between competences and financial decisions and to establish its direction: financial knowledge increases the probability of acquiring shares, fixed income securities and units of investment funds, not the reverse. The analysis also identifies the importance of age and financial income in most of the financial decisions considered in this work.

The aim of this work is to make multiple contributions. It is one of the first studies in Spain that aims to relate the financial competences of individuals with their financial decisions for a broad set of financial assets. While previous studies point out the importance of financial education in the acquisition of financial products, highlighting studies focused on the decision to purchase pension schemes, which are products that are fundamentally designed to save in anticipation of a future contingency (retirement), the findings of this work show that the financial education of individuals plays a particularly important role in the decision to acquire other financial assets such as fixed income and equity securities, either directly or through an investment fund. Investment funds are not so strongly perceived as hedging products but would be considered more the result of an ordinary investment decision based mainly on a valuation of the risk and return of the assets and the investment term. The results lead us to the conclusion that an individual's financial education is important to ensure that they make the best decisions based on their preferences. Thus, being able to identify the characteristics of individuals (in addition to their financial knowledge) that make them more likely to choose a particular product can help in the design of specific financial education plans in the future. 


\section{Introduction}

Between 2016 and 2017, the CNMV and the Bank of Spain, with the collaboration of the National Institute of Statistics, carried out a Survey of Financial Competences (ECF by its Spanish abbreviation). ${ }^{2}$ This initiative was part of an international project coordinated by the International Network for Financial Education, under the auspices of the Organisation for Economic Cooperation and Development (OECD), whose objective is to measure the knowledge, attitudes and financial behaviour of the populations of a broad range of countries.

With this objective, the ECF presents a series of relevant characteristics through which a description of the aforementioned variables can be made for the adult population in Spain and their relationship with the financial system. The survey uses a sample of randomly selected individuals aged between 18 and 80 , representative of Spain as a whole, in order to measure their knowledge of economic and financial concepts, as well as their ability to save and their holdings of financial products. The ECF also collects information on the demographics and employment status of the survey participants, their portfolios, sources of income and aspects related to their savings. It provides data on household and main residence expenses, although this report focuses on the individual rather than the household.

This working document contains an analysis of the general and financial knowledge of the Spanish population and aims to relate this knowledge with savings levels and financial products held, using the data collected in the ECF. The work has several objectives: i) to quantify the financial knowledge of individuals, ii) to relate this knowledge to available demographic and economic characteristics, and iii) to study the determinants of the financial decisions taken (including the decision to save in general or to acquire a specific financial asset (savings account, pension scheme, investment fund, securities or fixed income assets), paying special attention to the potential relationship between the individual's financial skills and these financial decisions.

Section 1 of this report describes how financial and general knowledge scores are constructed. Both these scores measure the sample's understanding of the issues. In Section 2, the estimated scores are related to the individual's profile. Sections 3 and 4 describe the relationship between the propensity to save and acquire financial products among the Spanish population and these financial and general knowledge scores. Section 5 offers an empirical analysis of the importance of financial competences and other demographic characteristics in making decisions about savings and acquiring financial products. Section 6 contains the conclusions reached, the limitations of the study and future lines of research.

2 This survey was carried out as part of the Financial Education Plan for 2013-2017 and was included in the National Statistics Plan for 2016. 



\section{General and financial knowledge of the population}

As mentioned in the introduction, the ECF contains both questions related to the financial knowledge of individuals and to their cognitive skills. In this section, using the information on these questions, the knowledge of the individuals in the sample is classified as "general" or "financial" to obtain an overall score for each type of competence. In the following sections, an analysis is made of the relationship between these scores and a series of variables, both financial (savings, holding certain assets) and demographic (age, education, gender, etc.).

To obtain the general knowledge score, the questions asked to the respondents that relate to their cognitive skills (reading comprehension and ability to understand graphs and equations) have been used, as well as some questions related to the general economy:3, 4

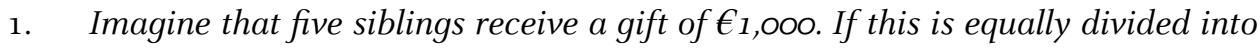
five shares, how much will each of them obtain?

2. On the card I am about to show you there is a chart with the number of births in the United States in ten-year intervals. During which period or periods did births fall in the United States?

3. A card containing text is shown. Can you indicate in which sentence in the text it is stated how the swimmer fed herself during the trial?

4. At what age did Cabañero start competing in swimming competitions?

5. Please choose the reply that best summarises the text you have just read.

6. Imagine that to produce five pieces of equipment, you need five machines working for five minutes. How long would a hundred machines take to produce a hundred pieces of equipment?

7. Who determines which goods and services are produced in Spain?

3 Questions from the ECF that are not directly related to relevant knowledge when making financial decisions have been included. One question for which the possible answers were ambiguous and could generate confusion was not included.

4 For more details on these questions and their possible answers see hhttps://www.bde.es/f/webbde/SES/ estadis/otras_estadis/2016/Cuestionario_ECF2016_WEB.en.pdf 
- Companies and governments.

- Consumers and governments.

- Companies, consumers and governments.

8. True or false: High inflation means that the cost of living is increasing rapidly.

9. This card shows the market value of three investment funds in which $€_{10,000}$ were invested six years ago. Assuming that fees and expenses are the same for all the funds, which fund obtained the best return after six years?

10. Which would have been the best fund with the best return if the investment had had to be withdrawn after three years?

An analysis of the answers to the previous questions shows that the proportion of individuals who correctly answer each of the questions is very uneven (see Figure 1). For example, in questions 1, 3 and 8 more than $80 \%$ of respondents answered correctly, while in question 6 only $23 \%$ did so.

\section{Number of correct answers to general knowledge questions}

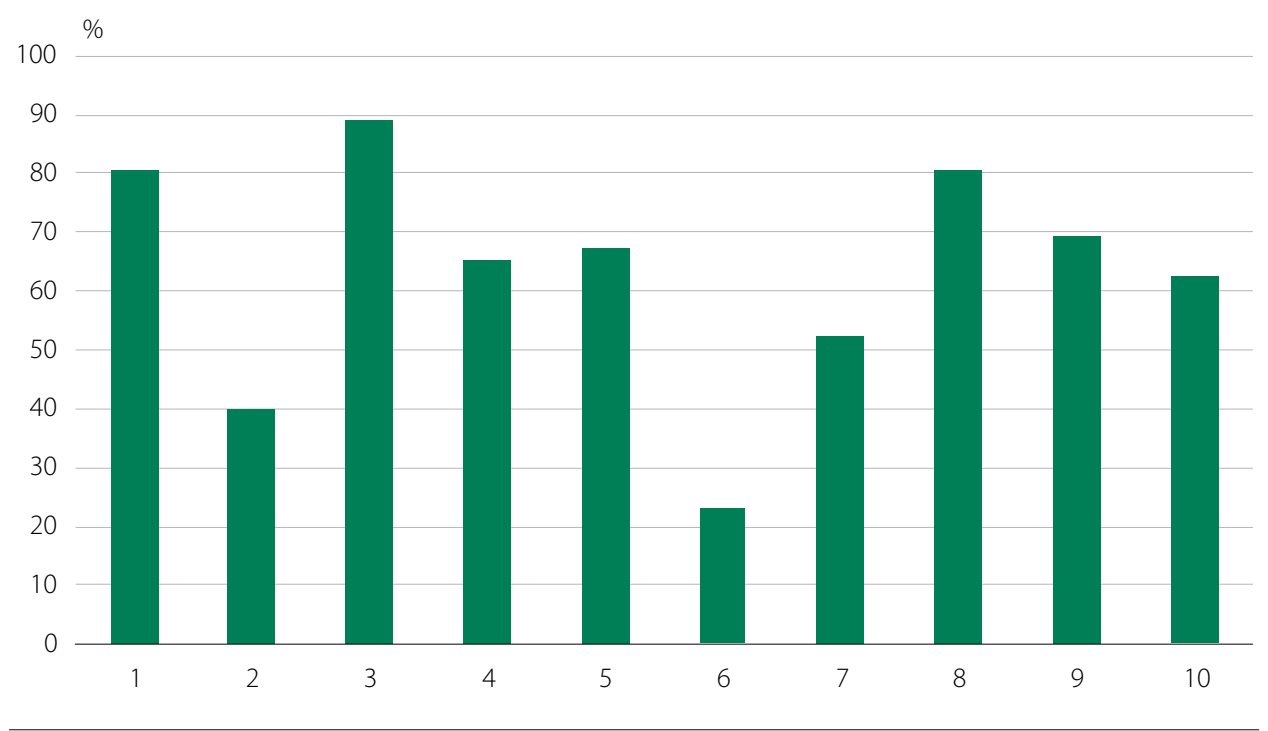

Source: ECF and CNMV.

To obtain a general knowledge score for the Spanish population, each individual in the sample was given a mark for each correct answer to the ten questions, obtaining a total average score of 6.30 out of 10. Additionally, general knowledge was classified into five groups with the aim of making their relationship with other variables more intuitive. These five groups were set up according to the marks obtained by the individuals and correspond to "very low" (score of o to 2), "low" (3 and 4), "medium" (5 and 6), "high" (7 and 8) and "very high" (9 and 10) knowledge.

Figure 2 shows how most of the population has medium to high general knowledge (33\% and $36 \%$ respectively), while only $4 \%$ has very low general knowledge. 


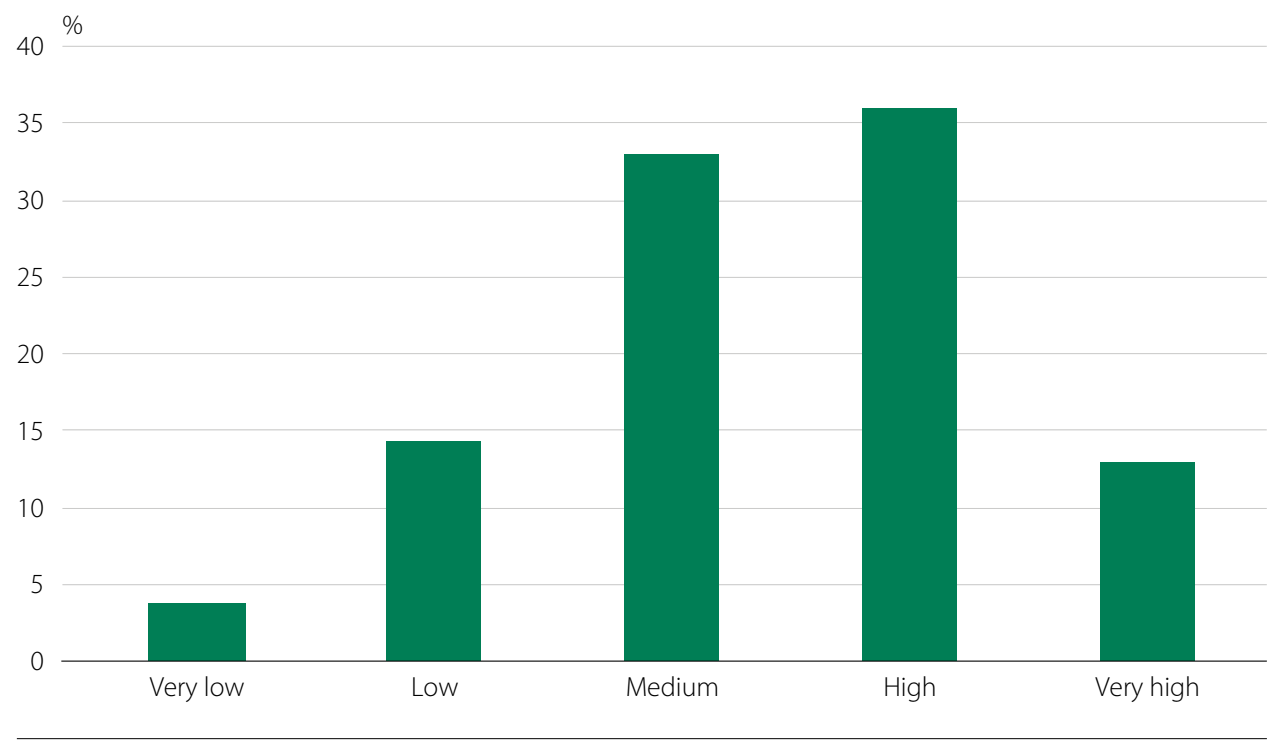

Source: ECF and CNMV.

For the financial knowledge score, the questions on different financial concepts, such as capitalisation, inflation and diversification, have been included:

1. Imagine that five siblings have $€_{1,000}$ to share and they will have to wait one year to get their share and that inflation in that year was $1 \%$. Within a year they will be able to buy:

- More than they could buy today with their share of the money.

- The same amount.

- Less than they could buy today.

- Depends on the type of things they wish to buy.

2. If you lend $\epsilon_{25}$ to a friend one night and the friend returns $\epsilon_{25}$ to you the following day, what interest have you charged on the loan?

3. Suppose you deposit $\epsilon_{100}$ in a savings account with a fixed interest rate of $2 \%$ per annum. In this account there are no commissions or taxes. If you make no other deposit in this account and do not withdraw money, how much money will there be in the account at the end of the first year, once interest has been paid?

4. Once again, if you make no deposit or withdraw, once the interest payment has been paid to you, how much money will there be in the account after five years: over $\epsilon_{110}$, exactly $\epsilon_{110}$, less than $\epsilon_{110}$ or it is impossible to say it with the information given?

5. True or false: An investment with a high return is also likely to be high risk. 
6. True or false: Generally, it is possible to reduce the risk of investing on the stock exchange by buying a wide variety of shares.

7. A 15-year mortgage typically requires higher monthly payments than a 30-year mortgage, but the total interest paid over the duration of the loan will be lower.

8. Who could benefit the most from an unexpected increase in inflation?

- A household that has a fixed interest rate mortgage.

- A bank that has granted a fixed interest rate mortgage.

- A household that lives from fixed income asset returns.

An analysis of the answers to the previous questions shows, in the same way as for the general knowledge questions, that the proportion of individuals who correctly answer each of the questions is very uneven (see Figure 3). However, in this case, the differences are somewhat less and the question about the unexpected increase in inflation (question 8) had the lowest number of correct answers $(32 \%)$. In contrast, one of the two questions referring to the simple interest rate (question 2) was answered correctly by almost all respondents.

As in the previous case, to obtain a financial knowledge score for the Spanish population, each individual in the sample was awarded a point for each of the correct answers to the eight questions. The total average score is 4.79 out of 8 , which is equivalent to 5.99 out of 10 . As for the general knowledge section, questions were classified into five groups, as follows: "very low" knowledge (o or 1 correct answers), "low" ( 2 or 3 correct answers), "medium" ( 4 or 5), "high" (6 or 7 ) and "very high" (8). As shown in Figure 4, almost $70 \%$ of the population has medium or high financial knowledge, while almost $25 \%$ of the population has very low or low knowledge.

Number of correct answers to financial knowledge questions

FIGURE 3

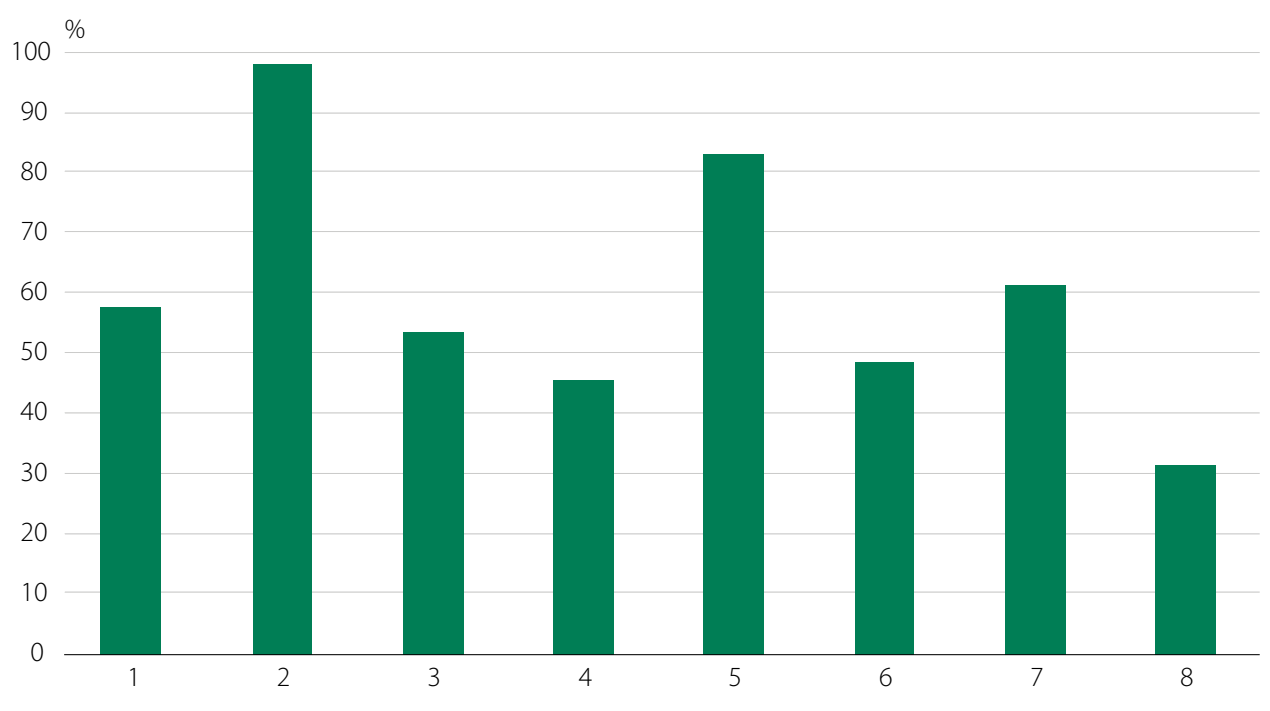

Source: ECF and CNMV. 


\section{Classification of the financial knowledge of the population}

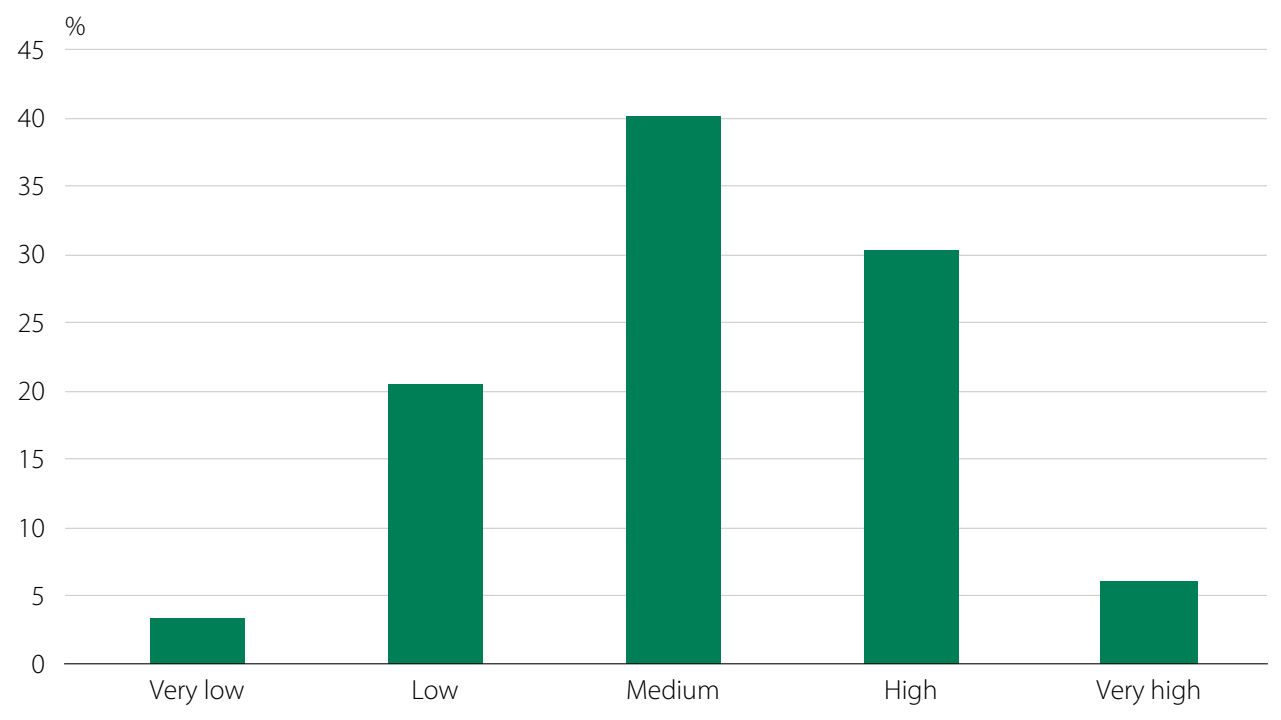

Source: ECF and CNMV. 



\section{Relationship between the individual's profile and general and financial knowledge}

This section shows the relationship between the knowledge of the population and certain demographic and financial variables, specifically age, gender, educational level and profile, and income level. Thus, Figure 5 shows the classification of general and financial knowledge according to age and gender. Overall, individuals aged between 65 and 80 show the lowest general and financial knowledge. In the first 3 age groups ( 18 to 34,35 to 44 and 45 to 54 ) the differences are minimal and most individuals in these age groups have medium and high levels of knowledge, although the percentage is higher in financial questions compared to general knowledge questions. In regard to gender, men have score higher for both general and financial knowledge. Thus, $84 \%$ of men have a medium level of general knowledge or higher compared to $79 \%$ of women. This percentage is $82 \%$ and $71 \%$, respectively, for financial knowledge.

\section{Classification of general and financial knowledge by gender and FIGURE 5 age group}

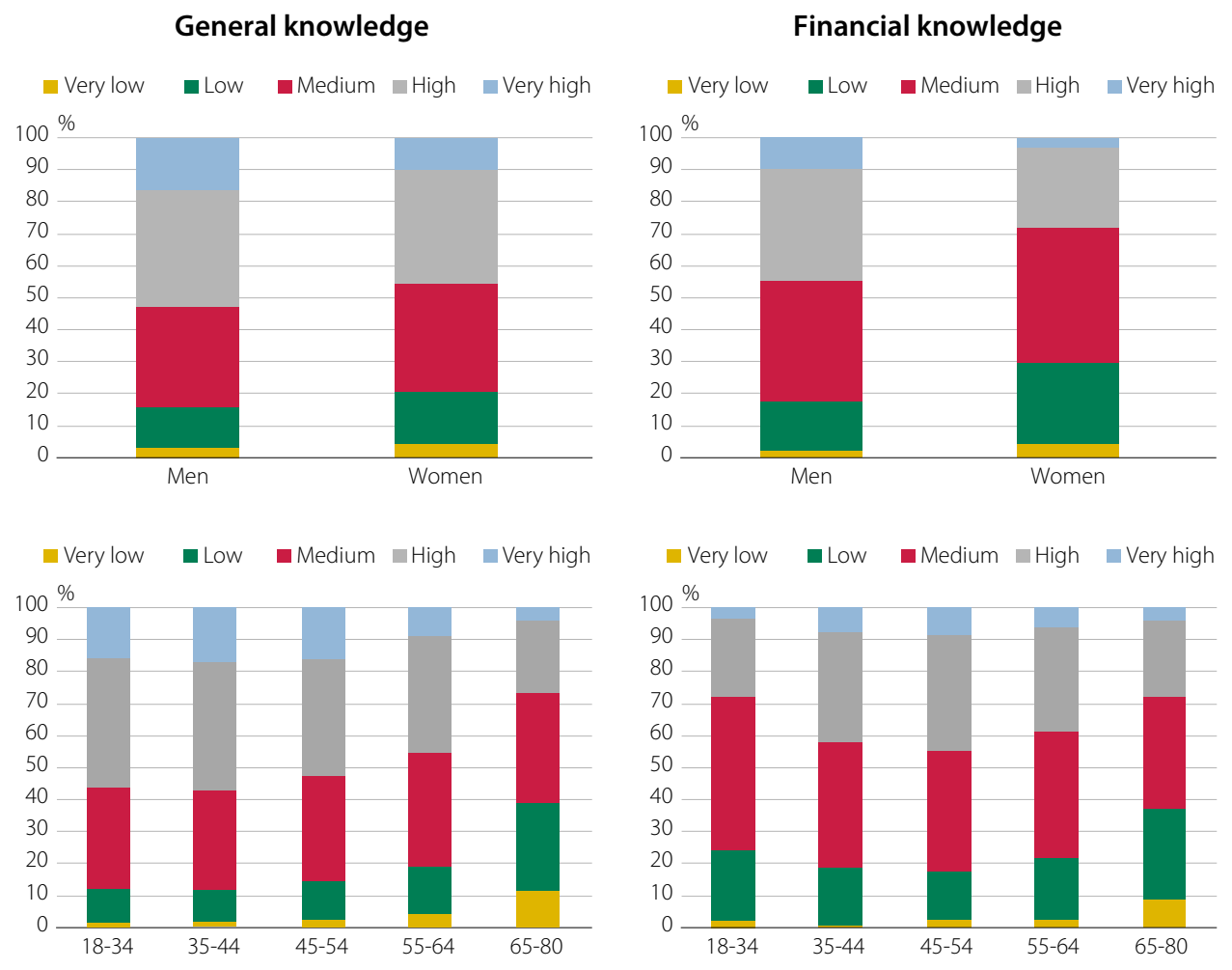

Source: ECF and CNMV. 
As could be expected, the education received by individuals is relevant to the general and financial knowledge scores they obtain. Figure 6 shows that the higher the level of education received, the greater the individual's knowledge. It can also be observed that their average score increases more sharply in first stages of education, with marginal growth stabilising from post-secondary education onwards. Likewise, it can be seen that for both general and financial knowledge, the higher the level of education, the greater the percentage of the population with high and very high knowledge (see Figure 7).

\section{General and financial knowledge based on education ${ }^{1}$}

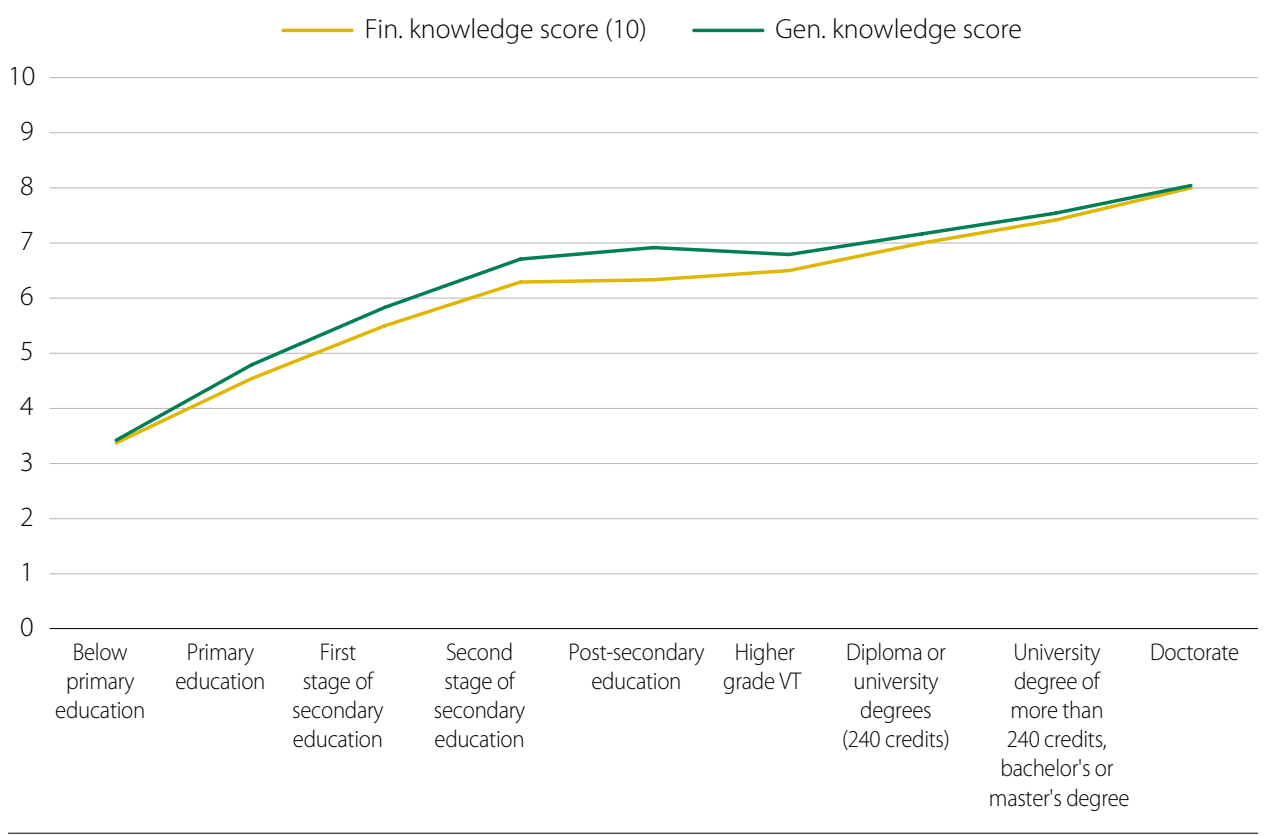

Source: ECF and CNMV.

1 In some cases, it is useful to specify what the studies referred to include (however, the answers given by the individual must be for the level of education achieved, not the level at which they are studying at that moment):

- Below primary education includes the illiterate population, people who have not been to school or completed primary education.

- Primary education also includes those who "can read and write but do not have any qualifications".

- The first stage of secondary education includes ESO (graduate in secondary education), EGB (school graduate), elementary secondary school diploma and programmes leading to a Level 1 and 2 professional qualification.

- The second stage of secondary education includes the Baccalaureate, BUP, COU, pre-university diploma, higher secondary school diploma, middle grade vocational training diploma and vocational training level I.

- Non-higher post-secondary education includes programmes leading to a level 3 professional qualification. Short-term programmes that require the second stage of secondary school education and similar.

- Higher level vocational training and similar includes higher level vocational training courses (higher technician), vocational training level II (FP II), industrial expert and chartered accountant.

- University diplomas, university degrees with 240 credits and similar include expert or specialist university degrees, with less than 60 ECTS (European Credit Transfer and Accumulation System) credits, which require a university degree.

- University degrees with more than 240 credits, BA, MA degree and similar include university MAs, with 60 or more ECTS credits, which require a university degree. 
General knowledge

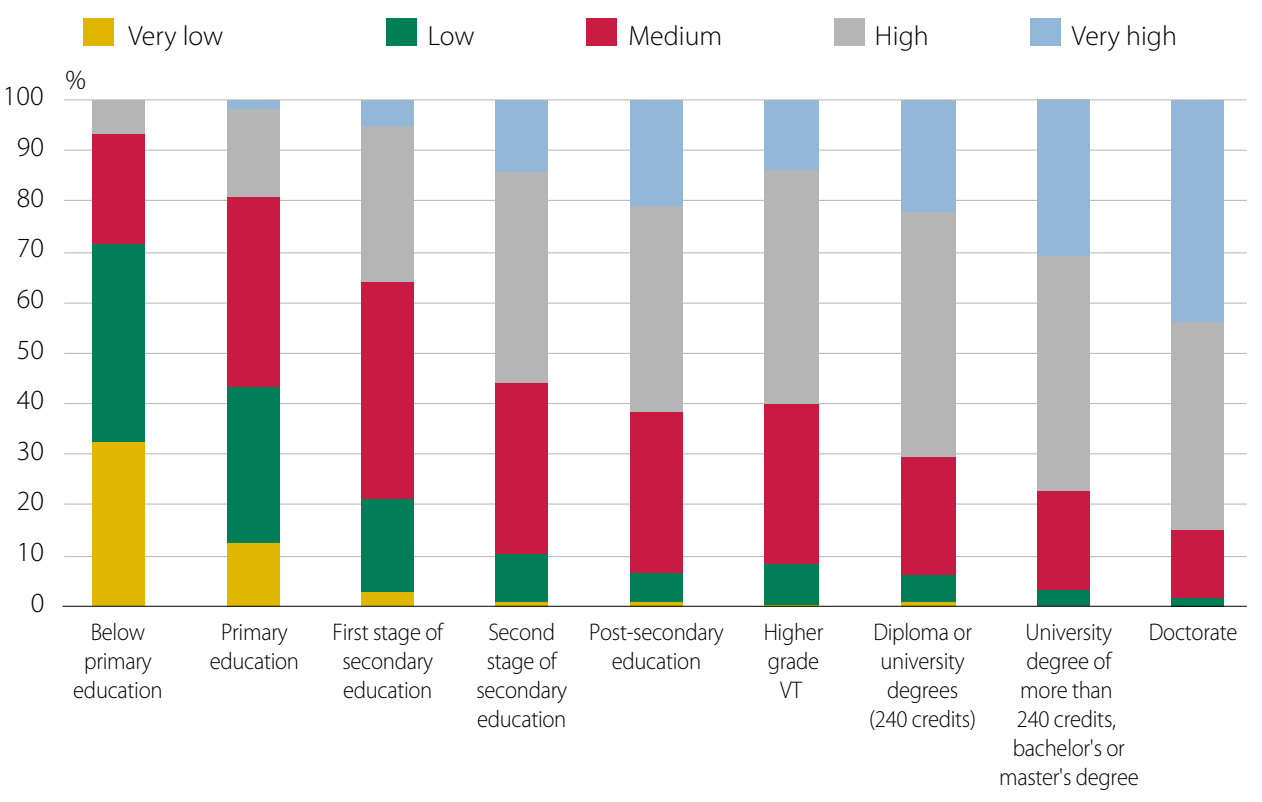

Financial knowledge

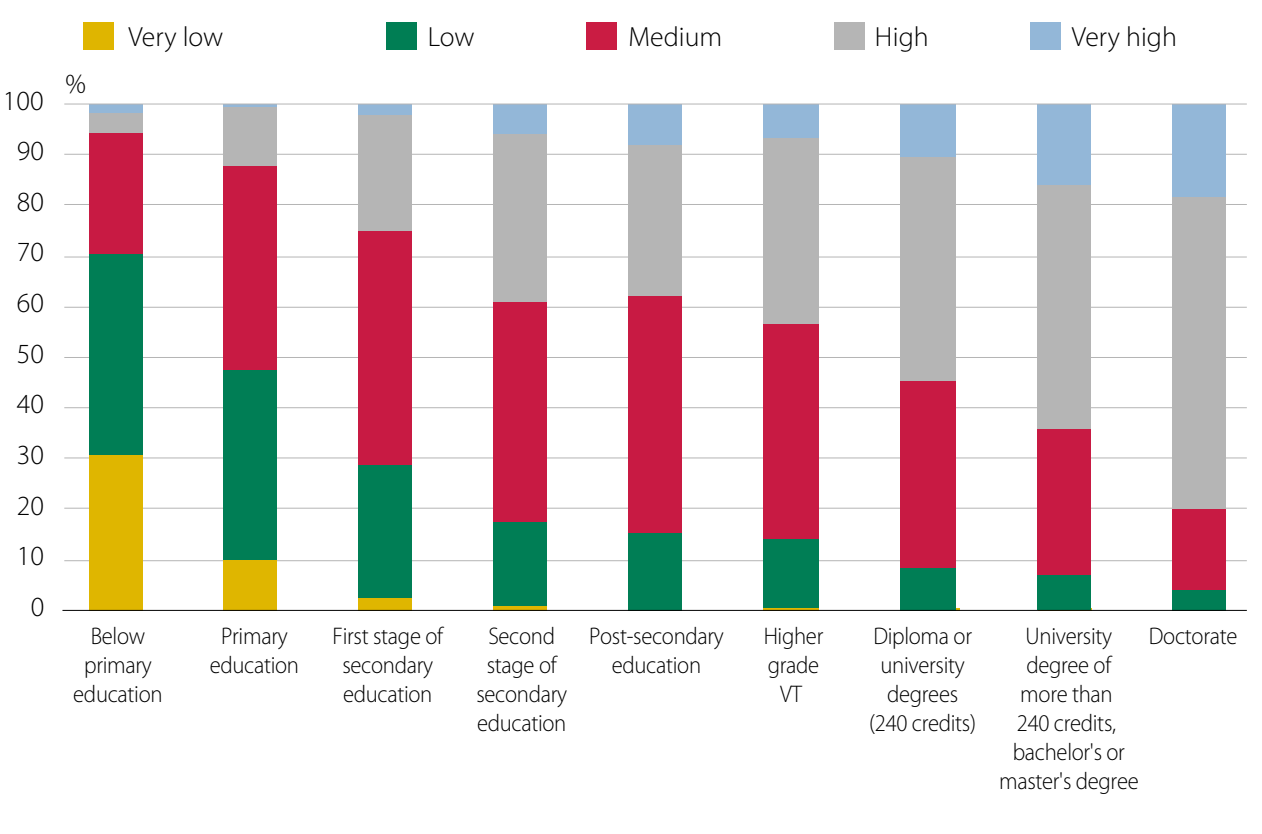

Source: ECF and CNMV.

Analysis of the sample of the population holding a university degree (approximately $14 \%$ ) is of interest to verify which branch of studies seems to have the most positive influence on financial knowledge. It can be observed that the average score for both types of competences (general and financial) corresponding to the different university degrees and the entire university group is higher than that obtained for the total sample (for the university sample, the average general knowledge score is 7.44 and the average financial score is 7.28 , compared to 6.30 and 5.99 respectively for the full sample). Table 1 shows that the qualifications with the highest scores in both financial and general questions are economics, business and administration, as well 
as experimental sciences, which include physics, mathematics, chemistry and biology. Figure 8 shows that for all branches of study the percentage of the population obtaining a low or very low score is small and most scores are high.

\section{Classification of knowledge according to university education}

\section{General knowledge}

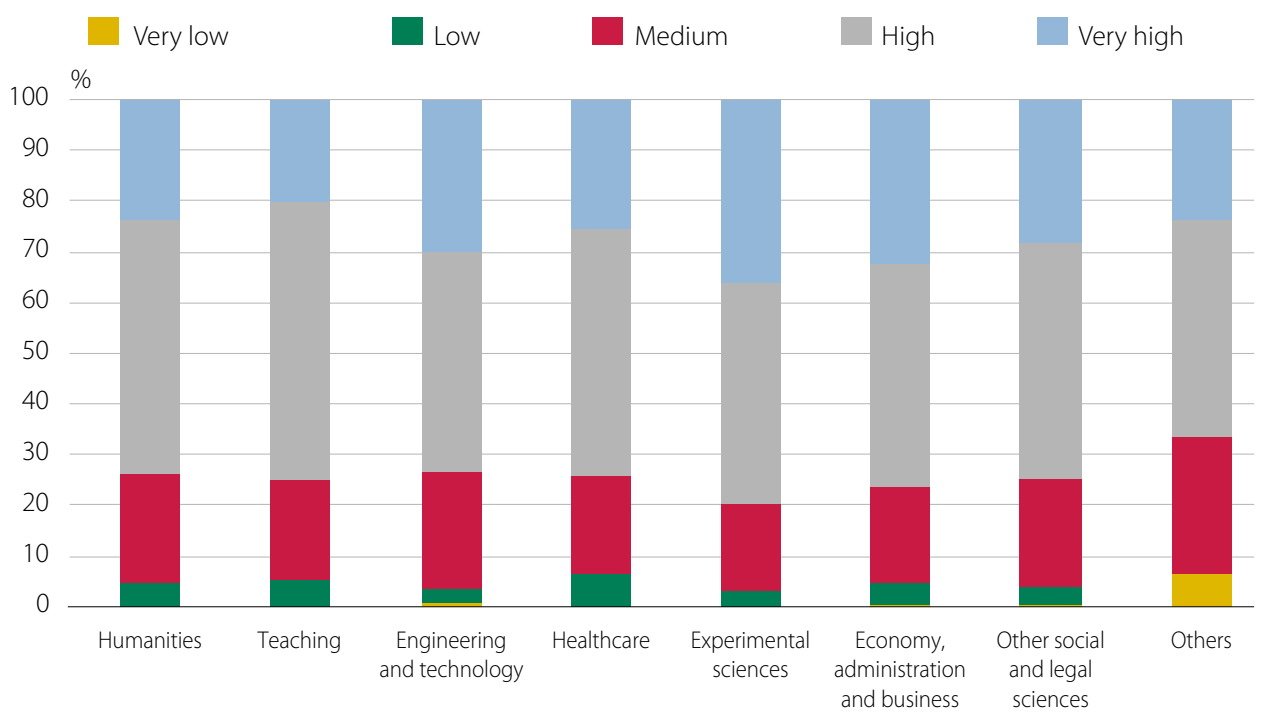

Financial knowledge

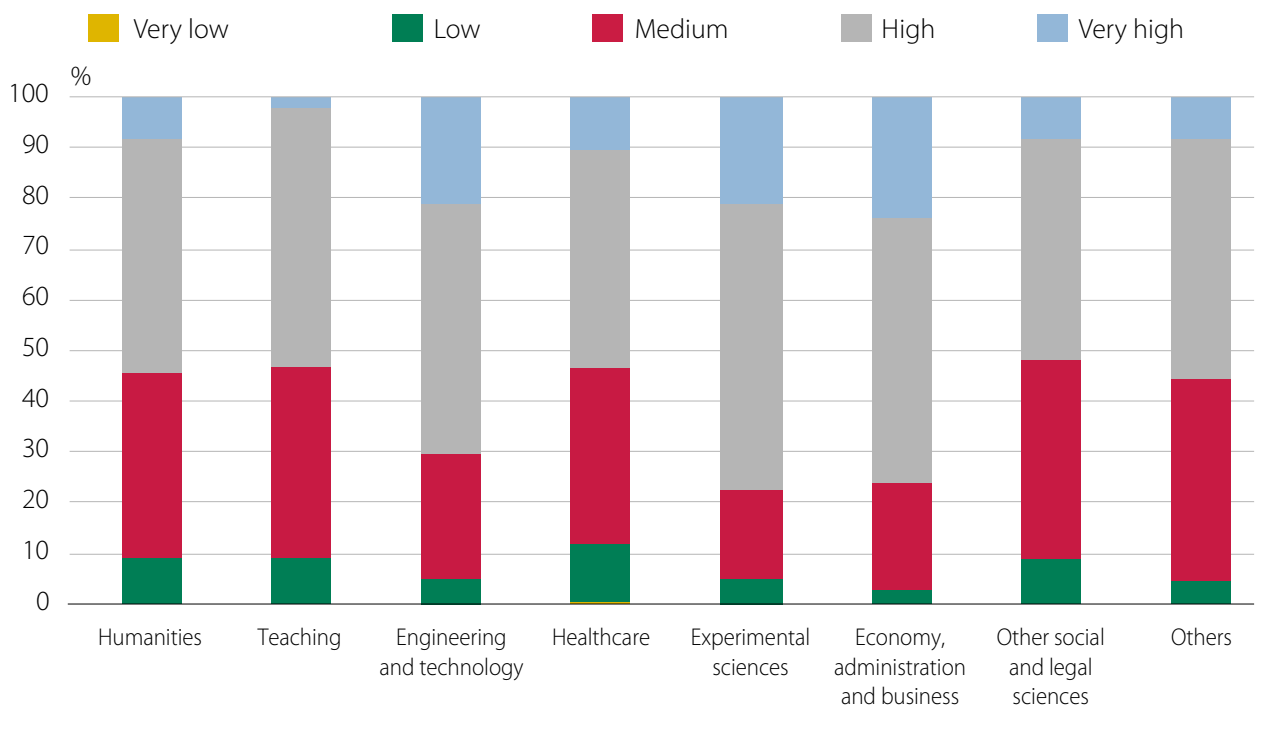

Source: ECF and CNMV. 


\begin{tabular}{lrr} 
University degree subject & $\begin{array}{r}\text { Average general } \\
\text { knowledge score }\end{array}$ & $\begin{array}{r}\text { Average financial } \\
\text { knowledge score }\end{array}$ \\
\hline Humanities $^{2}$ & 7.33 & 6.90 \\
\hline Teaching $^{1}$ & 7.40 & 6.84 \\
\hline Engineering and technology $^{3}$ & 7.44 & 7.63 \\
\hline Health sciences $^{4}$ & 7.42 & 6.87 \\
\hline Experimental sciences $^{5}$ & 7.75 & 7.89 \\
\hline Economic, business and administration $^{2}$ & 7.52 & 7.98 \\
\hline Other social and legal sciences $^{6}$ & 7.43 & 6.97 \\
\hline Other $^{2}$ & 6.85 & 7.01 \\
\hline Total population with a university qualification $^{2}$ & 7.44 & 7.28 \\
\hline Total population & 6.30 & $\mathbf{5 . 9 9}$
\end{tabular}

Source: ECF and CNMV.

1 Score out of 10.

2 History, Art, Languages, etc.

3 Architecture, Electronics, Mechanics, etc.

4 Medicine, Nursing, Pharmacy, etc.

5 Physics, Mathematics, Chemistry, Biology, etc.

6 Psychology, Sociology, Journalism, IT, Law, etc.

For the sample of individuals with a qualification in vocational training, the average score for both types of competences is also higher than that of the total sample. The same patterns are observed in many of the different vocational training (VT) courses except for those where the study content includes health, education, physical activities, security and the environment. However, the average score of individuals with a VT qualification is lower than that obtained by individuals with a university degree (6.79 and 6.47 vs 7.44 and 7.28 respectively). The distribution of average scores according to the branch of vocational studies is different for general and financial competences. Thus, building and civil works students obtain the highest scores in the general knowledge questions, followed by students of IT and communications. In contrast, individuals who have studied agriculture, mining, energy and water obtain the best financial knowledge scores by far. 


\begin{tabular}{llr} 
Vocational training subject & $\begin{array}{c}\text { Average general } \\
\text { knowledge score }\end{array}$ & $\begin{array}{r}\text { Average financial } \\
\text { knowledge score }\end{array}$ \\
\hline $\begin{array}{l}\text { Agriculture, Maritime-fishing specialisation, Mining, Energy } \\
\text { and Water }\end{array}$ & 6.75 & 7.33 \\
\hline Industry & & 6.36 \\
\hline Installation and maintenance, Electronics, Graphic arts, Crafts & 6.88 & 6.84 \\
\hline Building and civil works & 6.95 & 6.85 \\
\hline Hospitality and tourism, Transport, Vehicle maintenance & 7.44 & 6.20 \\
\hline Commerce and marketing, Administration and Management & 3 & 6.44 \\
\hline IT and communications & 6.67 & 6.97 \\
\hline Health, Education, Physical activities, Security and the & 6.78 & 5.78 \\
\hline Environment & 7.17 & 6.33 \\
\hline Other & & 6.81 \\
\hline Total population with vocational training & 6.79 & 6.30 \\
\hline Total population & 6.99 \\
\hline
\end{tabular}

Source: ECF and CNMV.

1 Score out of 10.

2 Food, wood, textiles, glass, chemicals, mechanical manufacturing, etc.

3 Commerce, banking entities, personal assistants, etc.

Lastly, Figure 9 shows the distribution of the financial competences score for each disposable income bracket. Here, it can be clearly observed that as the individual's income level rises the financial knowledge score also increases. However, this trend is not proportional. The distribution of financial literacy scores is similar among low-income individuals (less than $€_{9,000}$ per year and between $€_{9,000}$ and $€_{14,500}$ per year) and among high-income individuals. In the two groups of individuals with the lowest incomes, the average score is 4 (out of 8 ) and $50 \%$ have scores of between 3 and 5. In the two higher income groups, $50 \%$ of those surveyed have a score between 5 and 7 points, with the minimum score in both groups being $2 .{ }^{5}$ The greatest variation in knowledge is observed between the low-income and middle-income brackets. Among the latter, the $€_{26,0001-} €_{44,500}$ bracket stands out, where the average financial knowledge score (6) is much higher than the scores seen in the lower-income sections, but much greater dispersion is also observed. In this income bracket, $50 \%$ of individuals have scores of between 4 and 7 , and people who have not answered any question correctly and others who have obtained the highest score are identified.

5 This minimum score is obtained after eliminating the extreme data from the sample, which in this case is after discarding the $1 \%$ of individuals with the highest and lowest scores. 


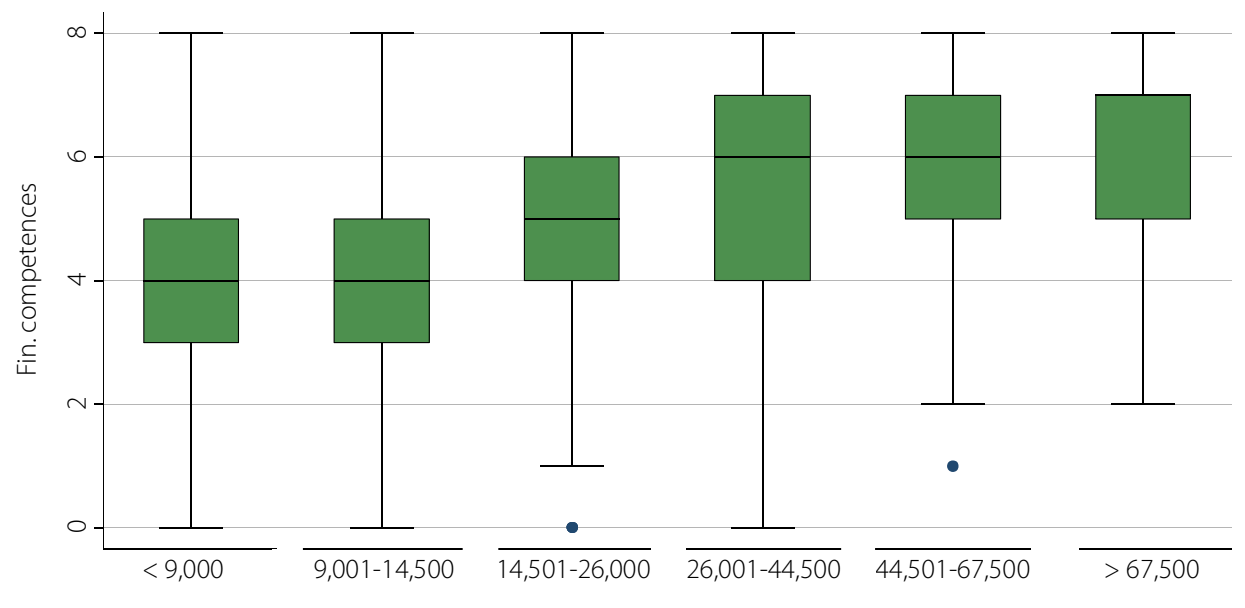

Source: ECF and CNMV. Income brackets in euros per year.

The information from the survey makes it possible to compare the individual's personal perception of his or her knowledge with the score obtained in the questions related to financial competences. In this way, a fairly objective deduction can be formed as to whether individuals undervalue or overvalue their financial knowledge. Respondents rated their financial literacy as "very low", "fairly low", "medium", "fairly high" and "very high", as we have done in this study with the computed score. If the two results are compared (Figure 10), it can be observed that $31 \%$ of the sample give themselves the same classification they later obtain, while $11.3 \%$ overestimate their financial knowledge and $57.7 \%$ underestimate it. Therefore, the majority of the population make erroneous self-assessments, believing that their financial knowledge is lower than it actually is (see Table 3 for more details). This result may be explained, at least partially, by the fact that the questions asked could be classified as basic or medium level, as there were no advanced questions. ${ }^{6}$

6 For examples of the differences between basic and advanced financial matters, see Van Rooij, M., Lusardi, A. \& Alessie, R. (2011). "Financial literacy and stock market participation". Journal of Financial Economics Vol. 101, No. 2, pp. 449-472. 
Difference between financial knowledge score and the perception of financial knowledge

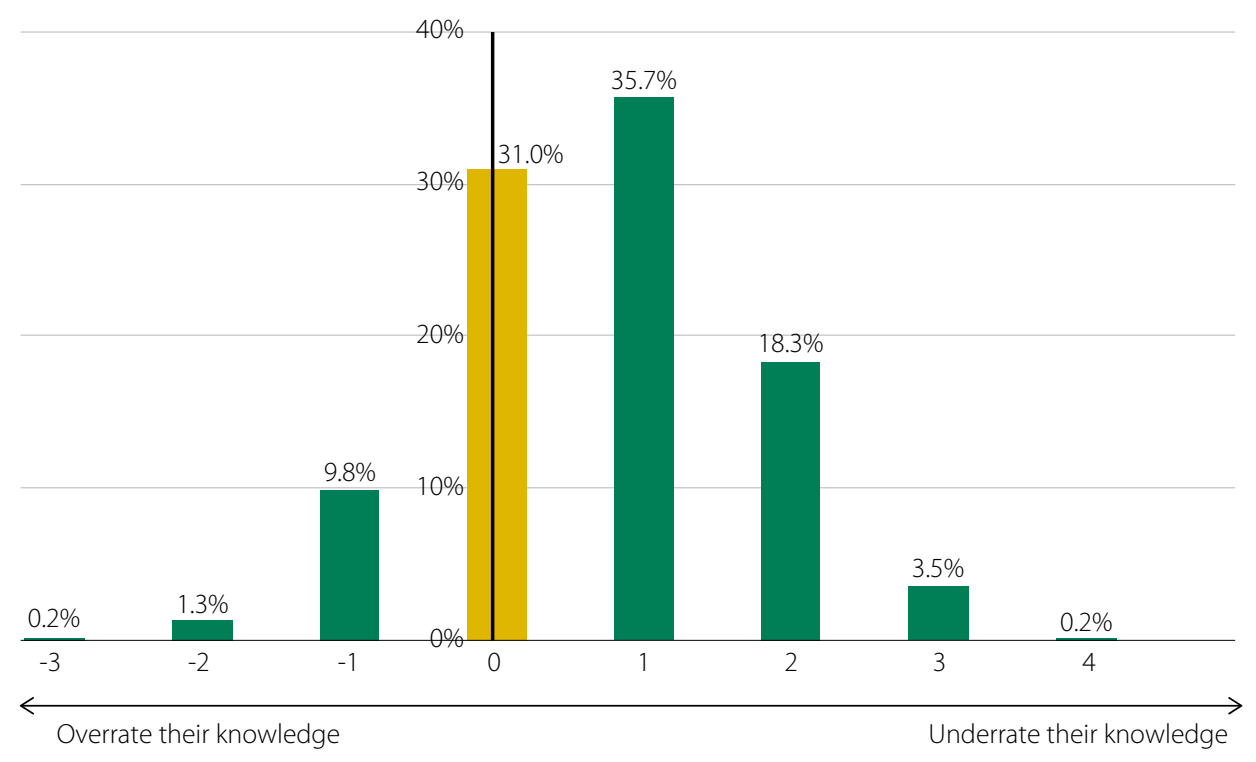

Source: ECF and CNMV.

Personal perception of financial knowledge compared to the financial TABLE 3 knowledge score obtained

$\%$

\begin{tabular}{|c|c|c|c|c|c|c|c|}
\hline \multirow{5}{*}{$\begin{array}{l}\text { Financial } \\
\text { knowledge } \\
\text { score }\end{array}$} & & \multicolumn{6}{|c|}{ Personal perception of financial knowledge } \\
\hline & & Very low & Low & Medium & High & Very high & Total \\
\hline & Very low & 1.9 & 0.7 & 0.6 & 0.0 & 0.0 & 3.2 \\
\hline & Low & 6.1 & 6.7 & 6.9 & 0.4 & 0.1 & 20.3 \\
\hline & Medium & 6.8 & 12.2 & 19.0 & 1.8 & 0.3 & 40.2 \\
\hline & High & 2.6 & 8.0 & 16.1 & 3.2 & 0.4 & 30.4 \\
\hline & Very high & 0.2 & 0.9 & 3.4 & 1.3 & 0.2 & 6.0 \\
\hline & Total & 17.5 & 28.6 & 46.1 & 6.8 & 1.0 & 100.0 \\
\hline
\end{tabular}

Source: ECF and CNMV. 


\section{$3 \quad$ Attitudes towards saving}

The savings that individuals make can be related to multiple variables, including their income, personal status, attitude towards spending and saving or the financial knowledge they possess, among others. This section describes the attitudes towards saving of the individuals taking the ECF and their effective decisions to save. It also provides a preliminary analysis of the potential importance of financial knowledge and other relevant variables, such as income, in these financial decisions.

In the first place, considering the way in which respondents make their decisions about money, both in their day-to-day lives and over the long term, an indicator of individuals' own perceptions of their attitude towards saving has been included. The ECF questions used in this area are the following:

1. Before buying anything, I carefully consider whether I can afford it.

2. I tend to live for today, without thinking about the future.

3. I prefer spending money now than saving it for the future.

4. I pay bills on time.

5. I am prepared to risk a little money when saving or making an investment, if I can then obtain a better return in the future.

6. I carefully look after my financial affairs.

7. I have set myself long-term financial targets and strive to meet them.

8. Money is there to be spent.

9. I worry about paying my usual expenses.

10. I am too indebted right now.

11. I am satisfied with my current financial situation.

The information the respondents have provided on how each statement reflects their personal situation has been added to the personal savings perception indicator presented in Figure 11. Thus, it can be observed that $22 \%$ of the sample are moderately concerned about saving part of their income, while 70.5\% give a high level of importance to personal savings. It can be concluded that the general population gives high importance to the concept of saving, although this indicator reflects individual opinions about saving and not the savings that are actually made. 
$80 \%$

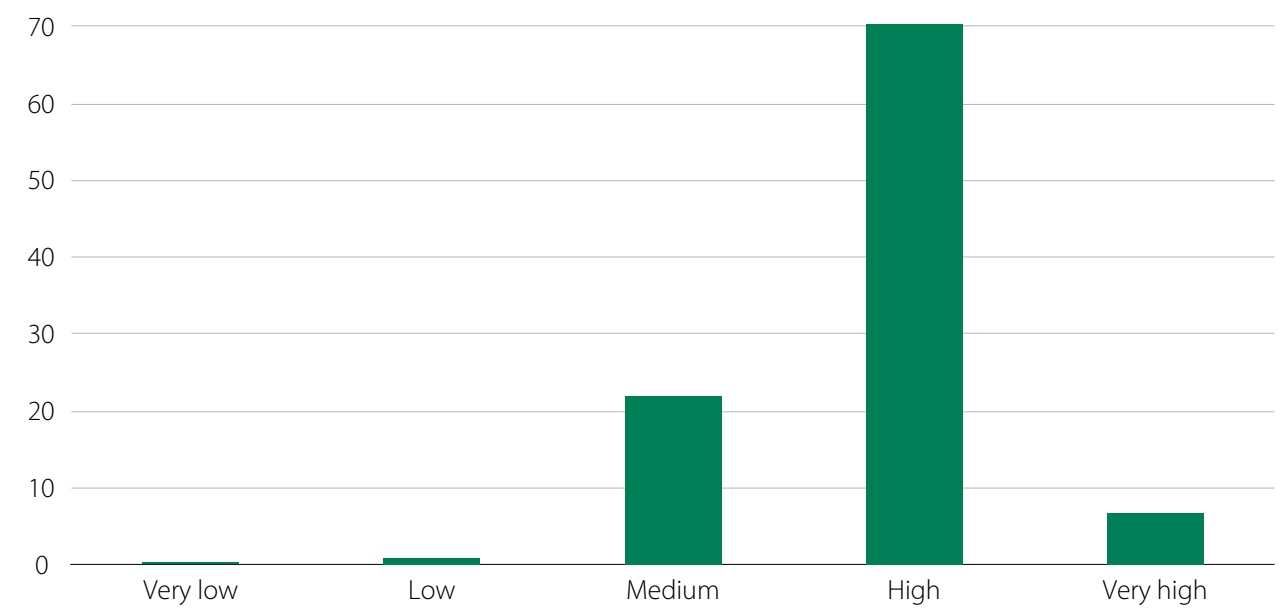

Source: ECF and CNMV.

Attitude towards saving: level of impatience ${ }^{1}$

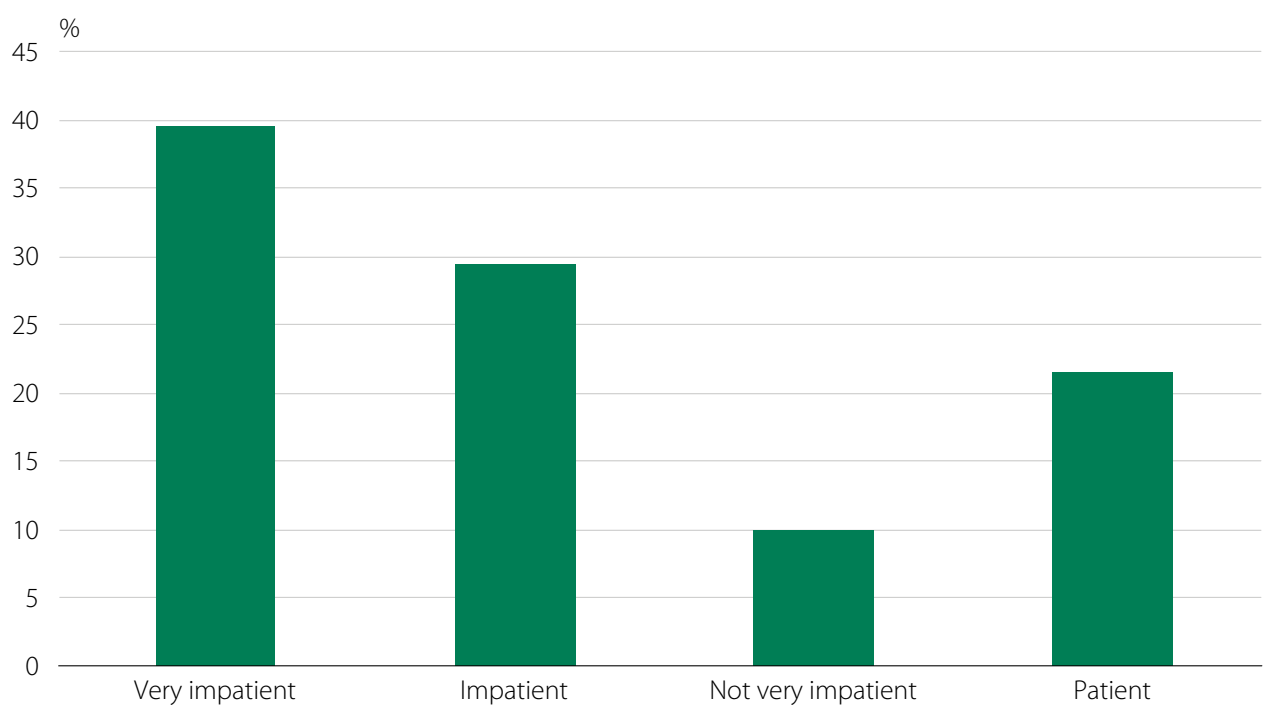

Source: ECF and CNMV.

1 The data in this graph are obtained from three related questions in the ECF that ask the individual to choose between different amounts of money to receive today or in a year's time. The answers to these preferences assess the individual's level of impatience to receive the amounts or to wait to make them profitable in the period of a year (and to save that difference in a certain way). The questions are as follows:

- Suppose they offer you $€ 2,000$ today. However, if you wait a year, they would offer you $€ 2,200$. In both cases, you would be fully certain to receive the money. What would you choose: $€ 2,000$ today or $€ 2,200$ in a year's time?

- If the answer to this question is $€ 2,000$, the next one would be: Now suppose that if you wait a year, they would offer you $€ 3,000$. In both cases, you would be fully certain to receive the money. What would you choose: $€ 2,000$ today or $€ 3,000$ in a year's time?

- If the answer to the first question was $€ 2,200$, the next one would be: Now suppose that, if you wait a year, they would offer you $€ 2,100$. In both cases, you would be fully certain to receive the money. What would you choose: $€ 2,000$ today or $€ 2,100$ in a year's time?

Individuals are defined as "very impatient" if they prefer to have the $€ 2,000$ today in all cases; "impatient" if they prefer the $€ 2,000$ today compared to $€ 2,200$ in a year's time (but would accept $€ 3,000$ in the future); "not very impatient" if they choose $€ 2,000$ today instead of $€ 2,100$ in a year's time (but would accept $€ 2,200$ in the future) and "patient" if they prefer to wait a year to receive more than $€ 2,000$ in all cases. 
Figure 12 reflects the population's attitude towards saving through one of the questions in the ECF in which individuals are asked whether they would prefer to receive an amount of money today or a greater amount in a year's time, with a yield ranging from $5 \%$ to $50 \%$ (see footnote to Figure 12). The responses obtained reflect that a significant portion of individuals, almost $40 \%$, have a very impatient attitude (they would prefer to have the money today rather than receive any greater amount in the future), while only around $20 \%$ could be considered patient or savers, preferring to wait a year to obtain a return of at least $5 \%$ (they would prefer any amount greater than $€_{2,000}$ in a year's time).

Despite the findings of the previous graphs, from which it can be concluded that individuals give high importance to saving part of their income, the data obtained directly from the ECF shows that approximately $39 \%$ of the population does not save. ${ }^{7}$ This may simply be due to cognitive differences between an individual's personal perception and what he or she actually does, but it may also be due, in this specific case, to an inability to save. In order to shed more light on the investment pattern of individuals, the remainder of this section looks at the potential relationship between general and financial knowledge and savings, as well as between individual income levels and savings. In regard to the first aspect, Table 4 classifies the individuals with each of the financial knowledge scores awarded as "savers" or "non-savers", and it can observed that as the score increases, so does the percentage of individuals who save. This positive correlation is also seen in Figure 13 for both the financial knowledge score and the general knowledge score.

\section{Financial knowledge and savings}

TABLE 4

$\%$

\begin{tabular}{lrr}
\hline Financial knowledge score & Percentage of savers & Percentage of non-savers \\
\hline 0 & 24 & 76 \\
\hline 1 & 29 & 71 \\
\hline 2 & 43 & 57 \\
\hline 3 & 51 & 49 \\
\hline 4 & 57 & 43 \\
\hline 5 & 63 & 37 \\
\hline 6 & 68 & 32 \\
\hline 7 & 76 & 24 \\
\hline 8 & 80 & 20 \\
\hline Total population & 61 & 39 \\
\hline
\end{tabular}

Source: ECF and CNMV.

7 The concept of "saving" is defined in one of the questions in the ECF, in which individuals are asked to indicate the different ways they have saved in the last 12 months, even if they do not have that money at the moment (for example, cash savings, current accounts, savings accounts, investment funds, etc.). One of the answers to this question is that "no savings have been made" and this is used to distinguish between savers and non-savers. 

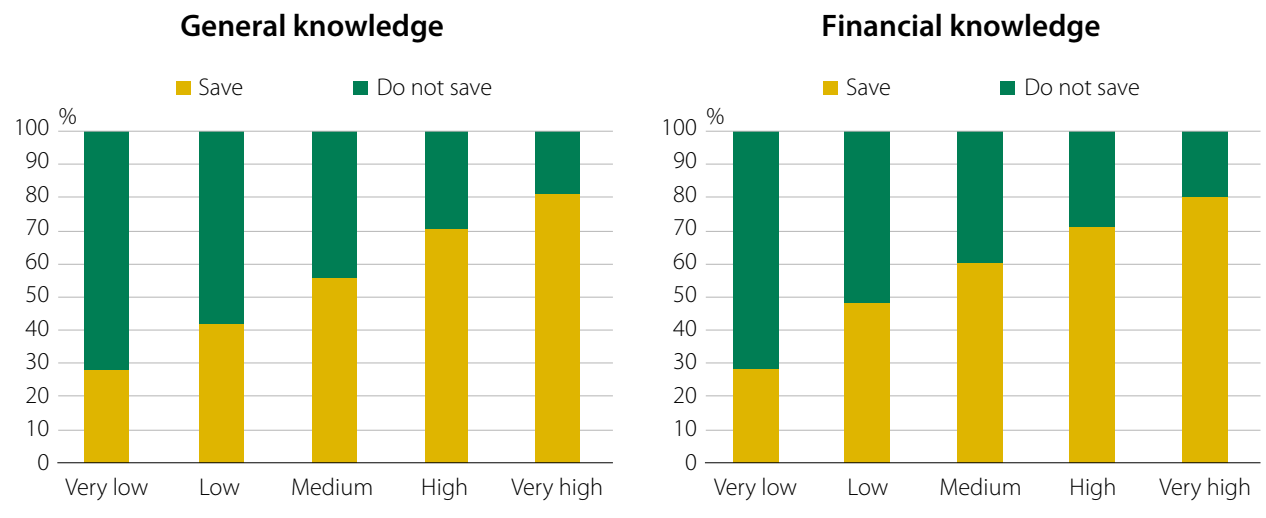

Source: ECF and CNMV.

It is also interesting to observe the most common means of saving among the population. To do this, using the same question as in the previous paragraphs (see footnote 4) to establish which individuals save and which do not, it is possible to determine how they have saved in the twelve months prior to responding to the question. ${ }^{8}$ Figure 14 shows that current accounts and cash are the most common types of saving vehicles $(38.8 \%$ and $23.3 \%$ respectively), followed by saving through a term savings account $(8.7 \%)$ and contributions to individual pension schemes $(6.6 \%)$. In contrast, saving through financial products that are a bit more complex than bank accounts (investment funds, securities or fixed income assets) occurs only in just over $3 \%$ of the population.

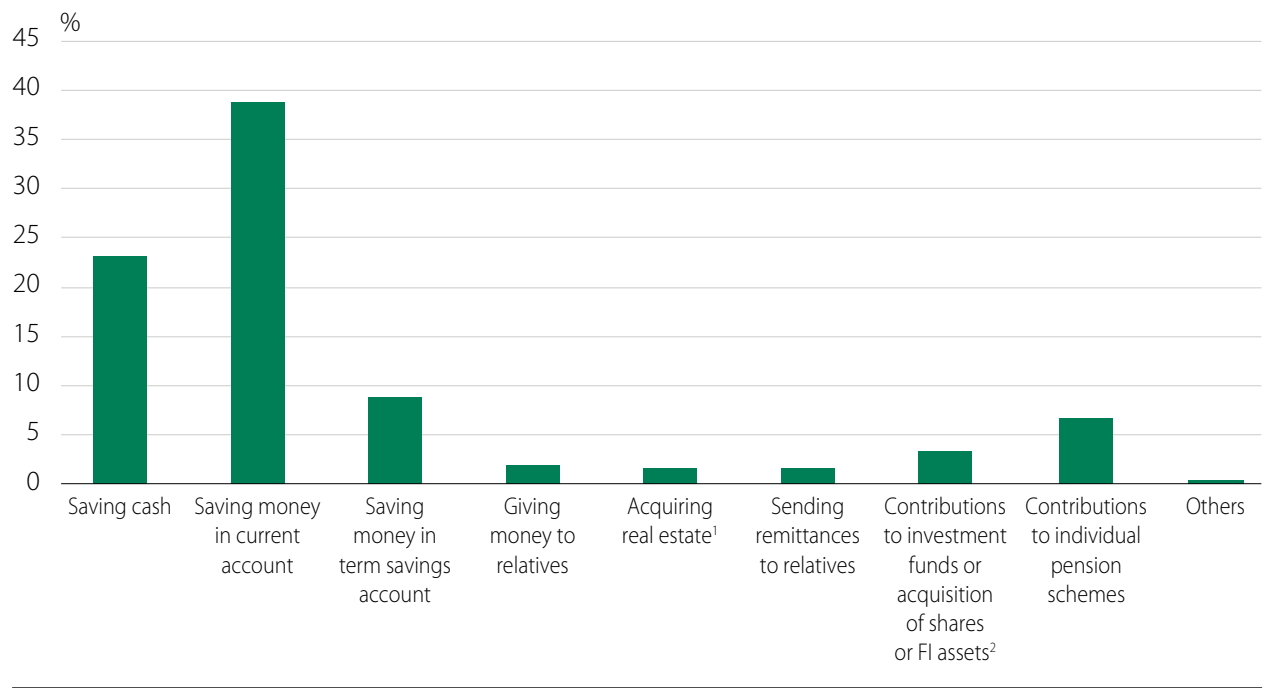

Source: ECF and CNMV.

1 Real estate property other than main residence (e.g. second home, premises, plot of land, etc.).

2 This question of the ECF includes jointly saving through contributions to investment funds, the acquisition of shares and fixed income assets.

8 The means of saving are not exclusive, as more than one format can be selected. 
We previously mentioned that approximately $39 \%$ of the individuals surveyed said that they did not save. $41 \%$ save using one single means, approximately $16 \%$ save by combining two means of saving and only $4 \%$ save using three or more means. Figure 15 shows these differences in the means of saving in relation to the knowledge of the population. Once again, preliminary analysis of the information suggests a positive correlation between individuals with greater general and financial knowledge and more diversified means of saving.

\section{Means of saving in relation to the knowledge of the population}

FIGURE 15

General knowledge

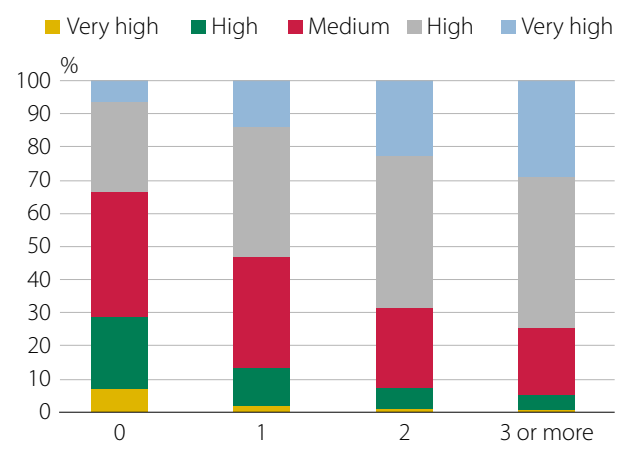

Financial knowledge

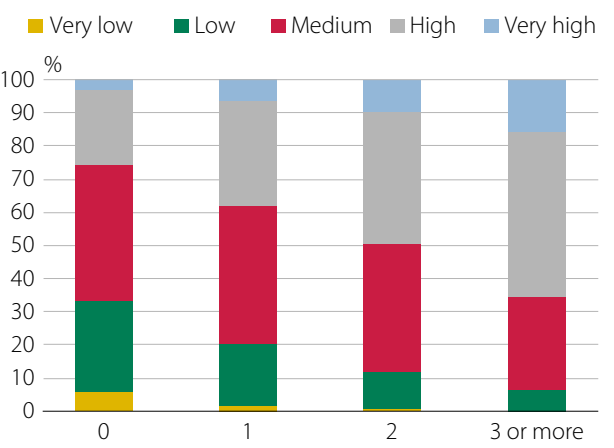

Source: ECF and CNMV.

The panels of Figures 16 to 21 include income levels in the analysis, which can obviously influence the proportion of savings effectively made. For analytical purposes, the gross income obtained by individuals in the year has been classified into six brackets and, as shown in the figures below, in all of them the percentage of savers tends to increase as the knowledge score rises, although this does not occur in all cases. It can also be observed that individuals with the highest income have more capacity to save and, therefore, the percentage of savers also increases with respect to the lowest income brackets.

Percentage of savers with gross annual income of less than $€ 9,000$ FIGURE 16

General knowledge

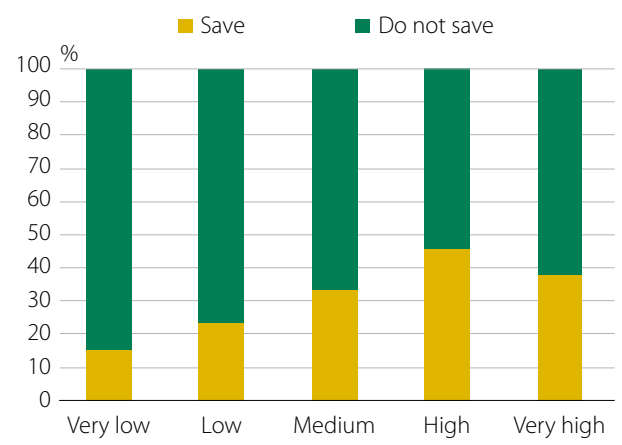

Financial knowledge

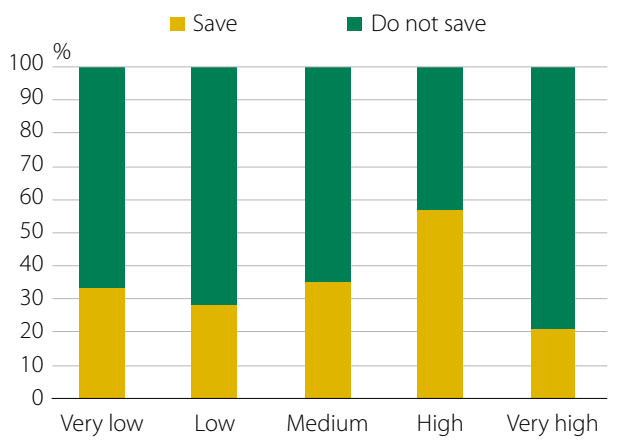

Source: ECF and CNMV. 
General knowledge

Save

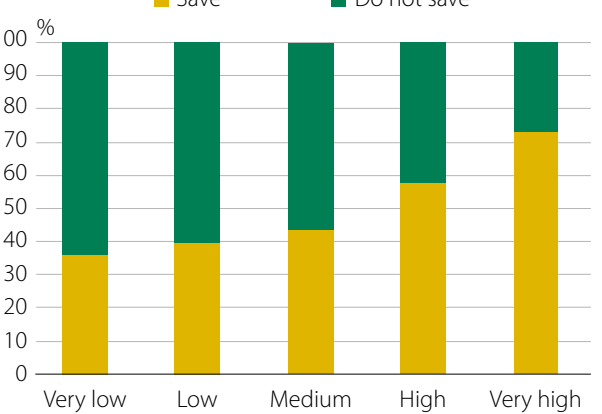

Financial knowledge

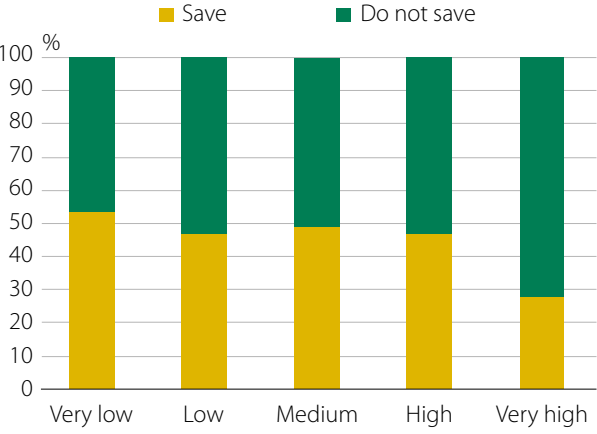

Source: ECF and CNMV.

Percentage of savers with gross annual income of $€ 14,501$ to $€ 26,000$

General knowledge

Save

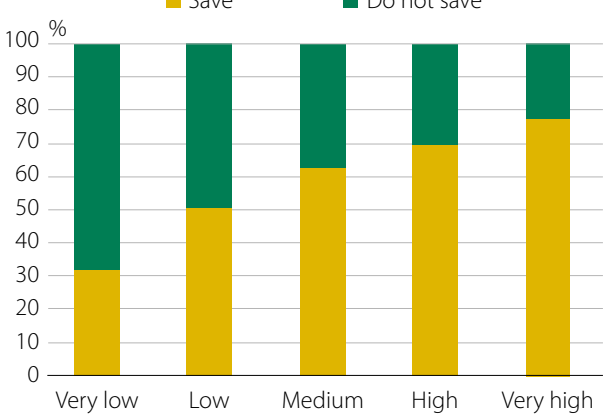

Financial knowledge

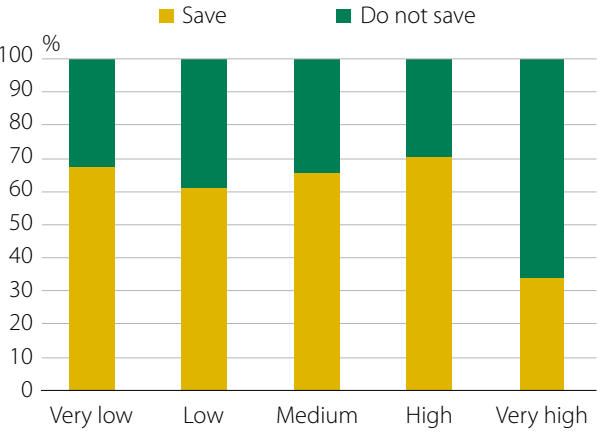

Source: ECF and CNMV.

Percentage of savers with gross annual income of $€ 26,001$ to $€ 44,500$

General knowledge

Save

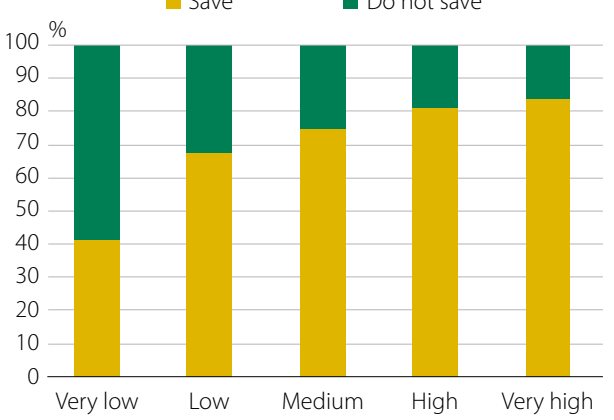

Financial knowledge

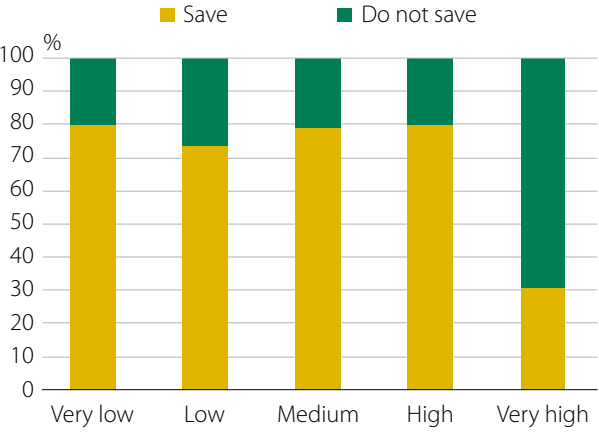

Source: ECF and CNMV. 
General knowledge

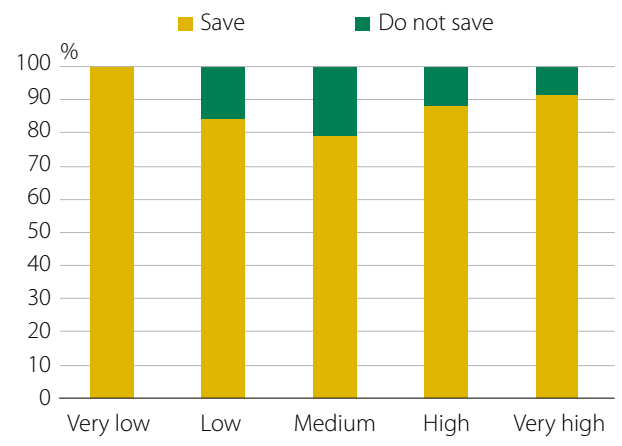

Financial knowledge

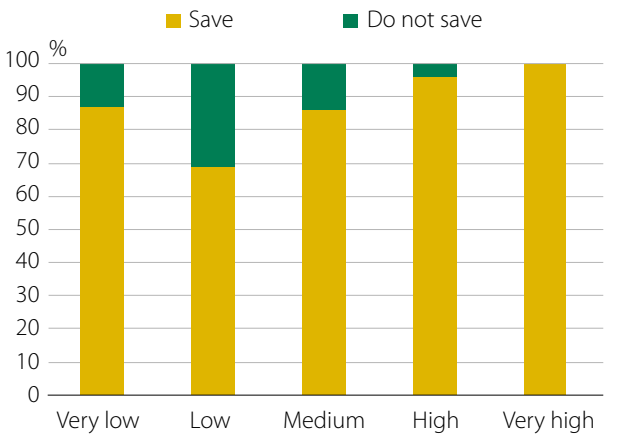

Source: ECF and CNMV.

Percentage of savers with annual gross income of more than $€ 67,500$ FIGURE 21

General knowledge

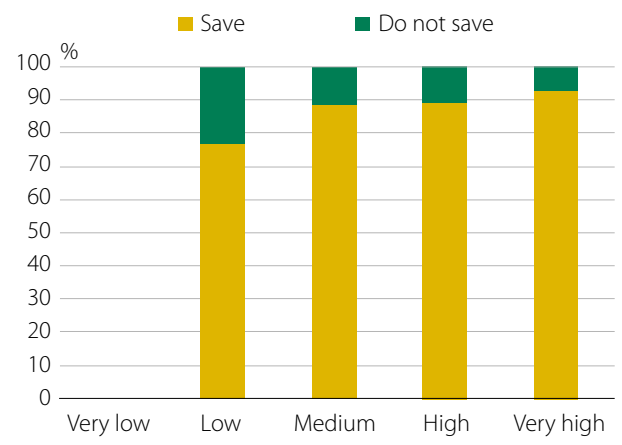

Financial knowledge

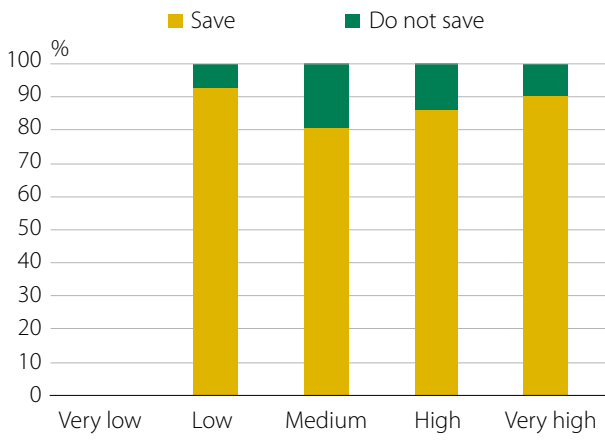

Source: ECF and CNMV. 



\section{Holding of financial products}

Certain survey questions shed light on the individuals' holding of financial products. Specifically, the respondents are asked about the following products: current accounts, savings accounts, ${ }^{9}$ mortgages, individual or company pension schemes, investment in investment funds, shares, public or private fixed income assets, life insurance, medical insurance, ${ }^{10}$ personal loans and credit cards. ${ }^{11}$ For the purpose of this analysis, for each of these products it is considered that individuals have invested in a specific asset if they own it at the time of the survey or in the two years prior to the survey even if it is no longer in their portfolio. Thus, Figure 22 shows that practically all of the respondents have current accounts (or have had a current account in the last two years). The next most common financial product is credit cards $(58 \%)$, followed by mortgages, life insurance, and savings accounts (approximately $30 \%$ of the sample state they own these products). Investments in shares, investment funds and public and private fixed income assets are less frequent (14\%, $9 \%$ and $2 \%$ respectively). ${ }^{12}$

Investing in certain financial assets could be conceived as a form of saving, which will be more diversified and could be more efficient if more than one type of product is held in the portfolio. To assess the level of diversification, the following financial assets have been considered: savings accounts, pension schemes, shares, investment funds and public or private fixed income assets. Figure 23 shows how more than half of the respondents do not hold any of these financial products, so they do not use this means of saving. In contrast, $25 \%$ of the respondents say that they hold or have held one of these products in the last two years, $12 \%$ two products and $7.6 \%$ three or more products.

9 This item includes term or sight accounts or deposits that cannot be used to make payments by card or cheque. In contrast, there are current accounts that are understood to be current accounts, savings books or other deposits that can be used to make payments by card or cheque.

10 For both health and life insurance the respondent must be the policyholder not just a beneficiary.

11 Credit cards such as Visa, Mastercard, American Express, etc. are included. Debit cards or cards issued by department stores for payments made only in their establishments are not considered.

12 It should be noted that some findings may not coincide with those observed in Figures 13 and 14 (both referring to individual savings). This is due to the period of time that has been taken into account: while for this item "assets held" refers to those held at the time of the survey or in the two preceding years, in the case of savings, it corresponds to the preceding 12 months. 


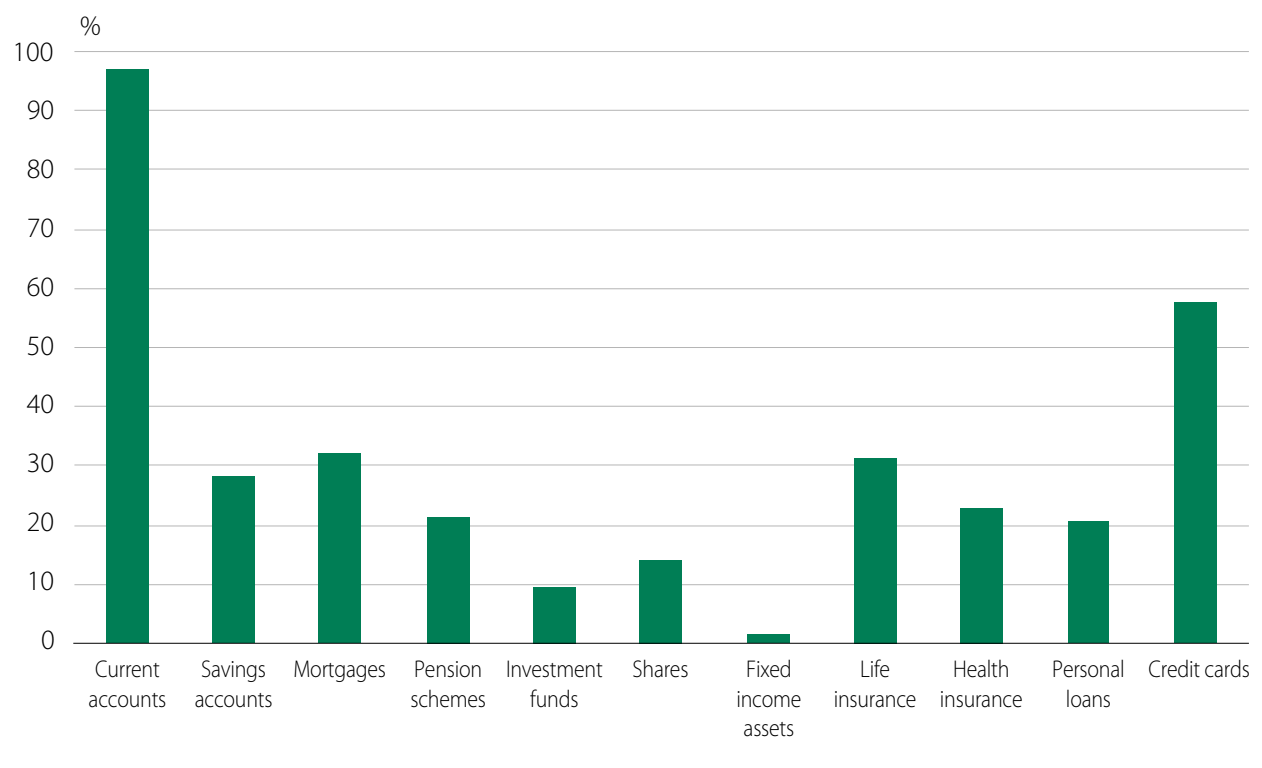

Source: ECF and CNMV.

1 For the following financial products, individual or joint holding is considered: savings accounts, mortgages, investment funds, shares, public or private fixed income assets, health insurance, personal loans and credit cards.

\section{Financial assets held currently or in the last two years}

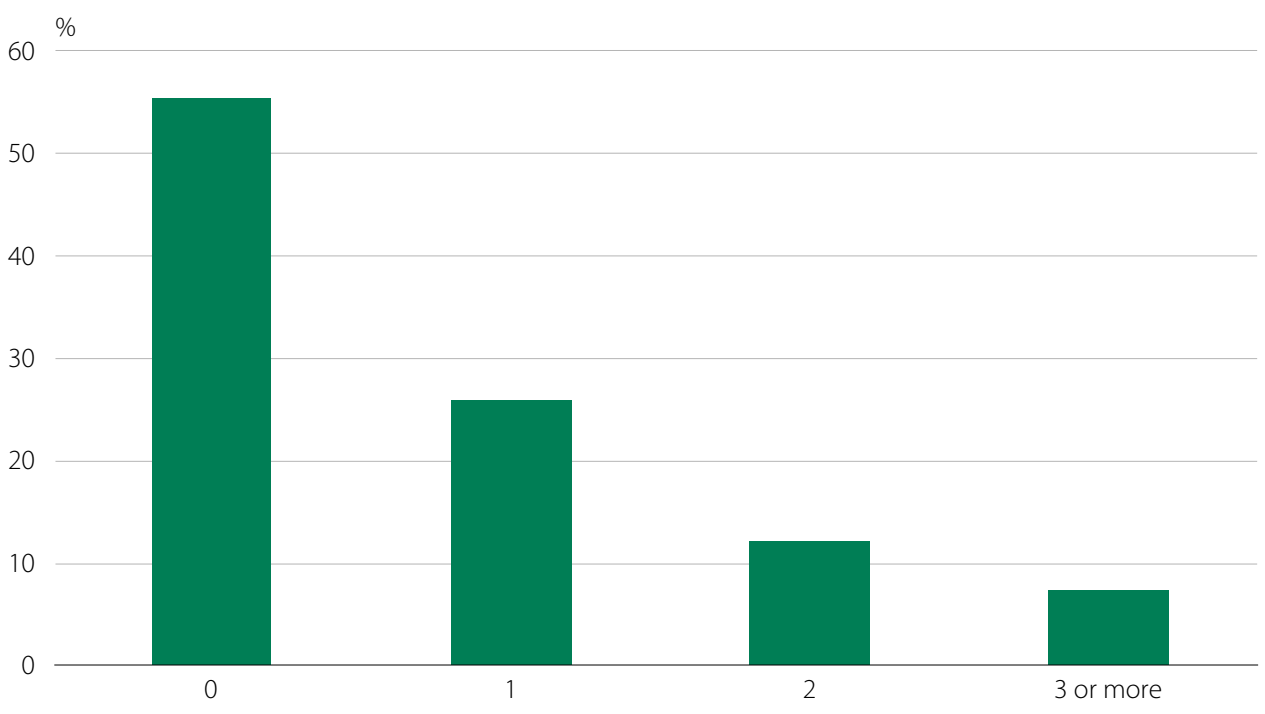

Source: ECF and CNMV.

The visual relationship between financial and general competences and the number of financial assets that respondents hold points to a potential positive correlation between the number of financial products and the proportion of individuals with high or very high competences. In the case of financial knowledge, within the group of individuals who do not hold any of the above assets, $25 \%$ have a high or very high financial score. This percentage increases to $67 \%$ for the group of respondents that hold three or more different financial assets (see Figure 24). Further, the percentage of people with low or very low knowledge decreases substantially as 
diversification between financial assets increases: $32 \%$ of individuals who do not hold any of these instruments belong to one of these two categories, while this percentage is $10 \%$ and $7 \%$ for groups holding two assets and three or more, respectively. In the case of general knowledge, as the amount of different assets held by an individual increase, the proportion of people with high or very high knowledge is greater.

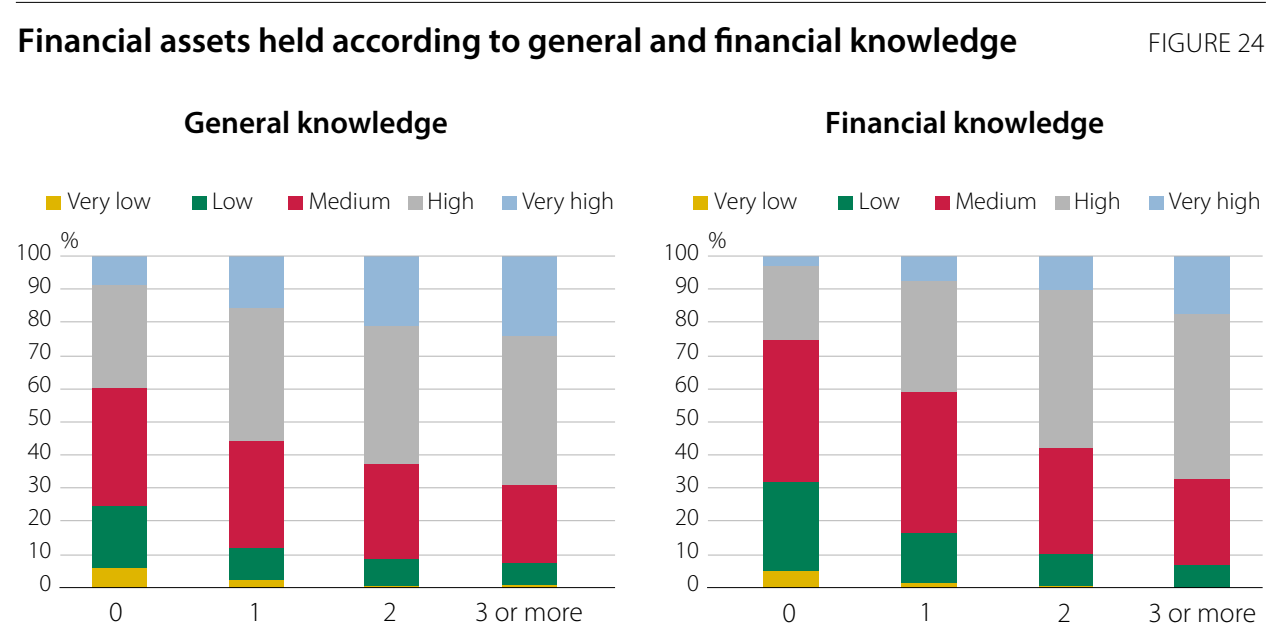

Source: ECF and CNMV.

Figure 25 represents the distribution of the financial knowledge score as a function of the number of assets in the individual's possession in order to look further into the positive relationship that appears to exist between greater diversification of assets and financial knowledge. It can be observed that the level of diversification increases in a proportion that is similar to the increase in the financial knowledge score until the number of financial assets is two. From then on, i.e. between individuals who invest in two financial assets and those who invest in three or more assets, the preliminary analysis does not throw up any significant differences in the level of financial knowledge. The greater differences in financial knowledge among individuals who have not invested in any assets in the past two years also stands out. In this group, 50\% of individuals have scores of between 3 and 6 (the highest interquartile range among those analysed) and people with extreme scores are also observed (score o-8), which is not observed in the other groups. 
Distribution of holdings of financial assets according to financial knowledge

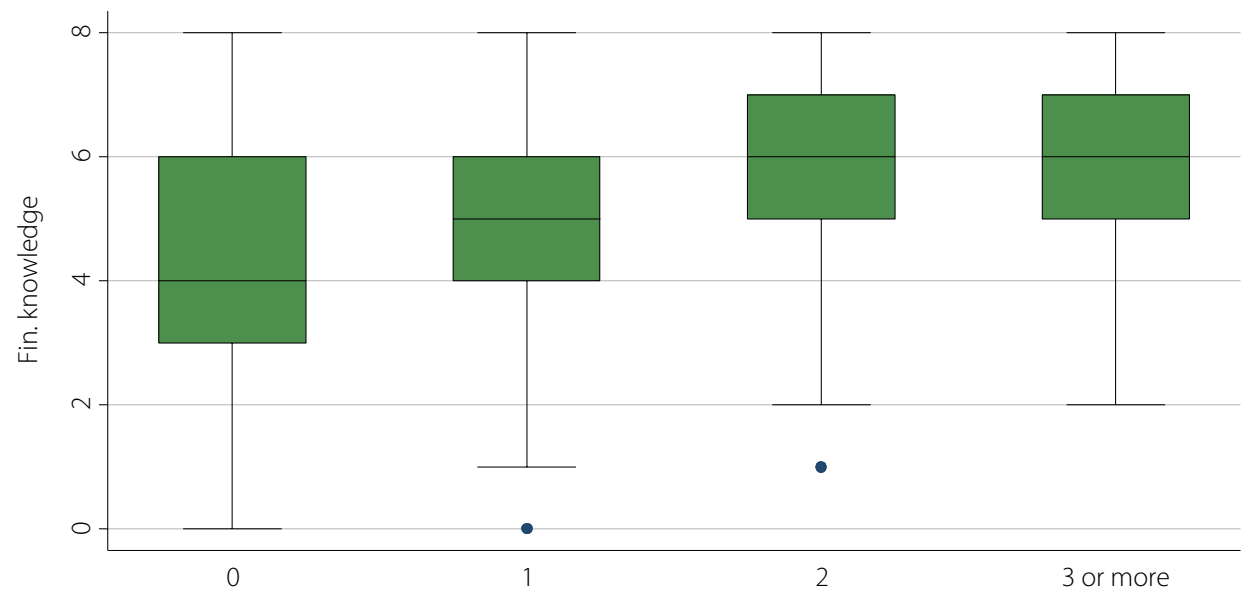

Source: ECF and CNMV.

Looking at the number of financial products held by individuals according to their household income, as might be expected, those with the highest income are observed to have the largest number of financial assets in their portfolios. Approximately $80 \%$ of individuals with an income of less than $€_{9,000}$ do not have any of the financial assets considered above, while this percentage falls significantly as income levels rise, dropping to $17 \%$ among individuals with an income of over $€ 67,500$.

\section{Holdings of financial assets according to household income}

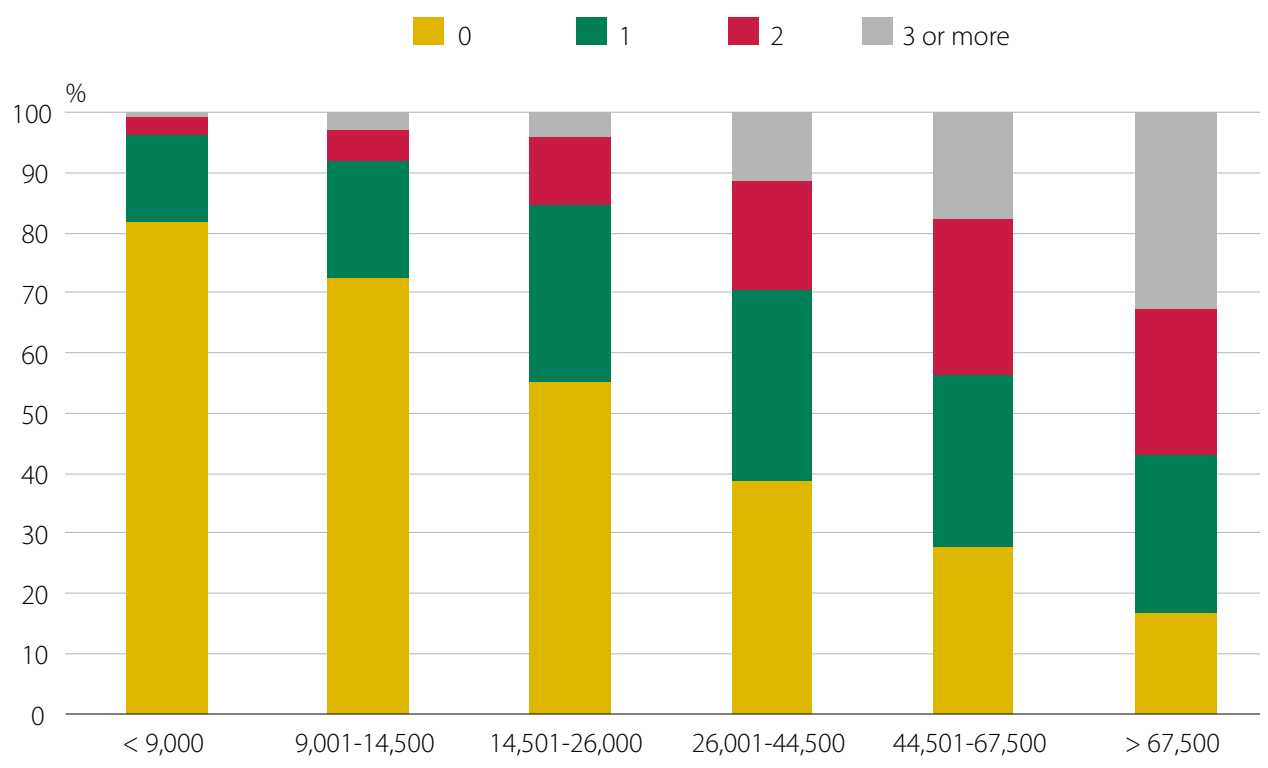

Source: ECF and CNMV. 


\section{Financial competences and saving and investment decisions}

This section analyses the importance of financial competences when individuals take financial decisions, in other words, their attitude towards saving and investing in the financial markets. Specifically, the importance of financial knowledge in financial decision-making is assessed through the following question: Are individuals with greater financial knowledge more likely to save and/or purchase certain financial products (i.e. savings accounts, pension schemes, investment funds, shares and fixed income assets)?

\subsection{Variables and methodology}

The dependent variables included in the analysis refer to individuals' attitudes towards saving and holdings of different financial products. Six dummy variables are defined: the saving variable takes the value of 1 if the individual states that they have saved in the last 12 months and o otherwise; and the savings account, pension scheme, investment fund, shares and fixed income variables take the value of 1 if the individual states that they currently hold or in the preceding two years have taken out or invested in a savings account or deposit (term or sight), an individual or company pension scheme, an investment fund, shares or public or private fixed income assets, respectively, and o otherwise.

To define the independent variable for financial knowledge, the methodology proposed by Van Rooij et al. (2011) is applied and an index for the eight questions in the ECF that assess financial competences has been constructed using the iterated principal factor method. In line with Van Rooij et al. (2011), to construct the index a differentiation is made between incorrect answers and "don't know/no answer" response, as this is important for refining the individual's level of financial competences (Lusardi and Mitchell, 2011a). Thus, two dummy variables have been constructed for each of the questions asked: a variable that takes the value of 1 if the question has been answered correctly and o otherwise; and a variable that takes the value of 1 if the response is "don't know/no answer" and o otherwise. As there are eight questions, the construction of the financial knowledge index considers a total of 16 variables. Factor scores have been computed using the Bartlett (1937) method and are shown in Table A.1 in the appendix.

Additionally, a set of independent variables has been defined to control for demographic characteristics that may influence financial decision-making. In all, 16 dummy variables have been defined that refer to the individual's age, education, gender, characteristics of the family unit, professional status and income. 
In regard to the methodology used, the following probit models are estimated:

$$
\mathrm{E}\left[D V_{i}^{*} \mid, F N_{i}, X_{i}\right]=\alpha_{0}+\beta_{1} F N_{i}+\beta_{2} X_{i}+\varepsilon_{i}
$$

where $D V_{i}$ is a vector of dummy dependent variables (savings, savings account, pension scheme, investment fund, shares and fixed income) that reflect the individual's attitude towards saving and holding financial products $i ; F N_{i}$ is the index that measures the individual's financial knowledge; $X_{i}$ is a vector of independent variables that reflect the individual $i$ 's demographic characteristics (age, education, gender, family unit, professional status and income); and lastly, $\varepsilon_{i}$ is the error term.

Secondly, to correct for the potential endogeneity problem of the financial knowledge variable (i.e. double causality), ${ }^{13}$ probit models are estimated using instrumental variables. This technique requires at least one variable to be found that acts as an instrument for the endogenous variable and that simultaneously meets the following conditions: i) it is correlated with the endogenous variable to be instrumented (relevance); and ii) it is not correlated with the error term (exogeneity).

In line with Van Rooij et al. (2011) the instrumental variable used is whether the individual has economics and/or business training. However, this instrument only simultaneously meets the conditions of relevance and exogeneity for the dependent variable saving. For the other dependent variables (savings account, pension scheme, investment fund and fixed income), a dummy variable is used as an instrument that takes the value of 1 if the approximate number of books in the individual's family home when he or she was ten years old was more than 100 and for the shares variable, the gender of the respondent. The exogeneity of the instruments has been validated through the Wald test of exogeneity (see Table 6).

The probit models with instrumental variables are defined as follows:

$$
\begin{gathered}
\mathrm{E}\left[D V_{i}^{*} \mid X_{i}, F N_{i}\right]=\alpha_{0}+\beta_{1} X_{i}+\beta_{2} F N_{i}+\varepsilon_{1 i} \\
F N_{i}=\delta_{1} X_{i}+\delta_{2} Z_{i}+\mu_{i}
\end{gathered}
$$

where $D V_{i}$ it is a vector of dependent variables (savings, savings account, pension scheme, investment fund, shares and fixed income); $X_{i}$ is a vector of exogenous independent variables (age, education, gender, ${ }^{14}$ family unit, professional status and income); $F N_{i}$ is the endogenous variable (financial knowledge); $Z_{i}$ is the vector of instrumental variables (training in economics/business, ${ }^{15}$ more than 100 books at age $10^{16}$ and gender $)^{17}$; and $\varepsilon_{i}$ and $\mu_{i}$ are the error terms.

13 In this context, double causality implies that individuals' financial knowledge can be improved through their involvement in the financial markets. In other words, the independent variable can be determined by the dependent variable, obtaining biased estimates through probit models.

14 With the exception of the dependent variable shares.

15 For the dependent variable saving.

16 For the dependent variables savings account, pension scheme, investment fund and fixed income.

17 For the dependent variable shares. 


\subsection{Results}

Table 5 shows the results of the probit models estimation. The results indicate that financial knowledge positively influences behaviours based on saving and holding financial products.

The models show different relationships in regard to the demographic characteristics of individuals. Thus, an analysis of the determinants of saving (Model 1) reveals that the probability of saving is lower the older the individual is and when they live with children. In contrast, individuals with a Baccalaureate qualification, higher level vocational training, a university degree and high income levels are more likely to save.

In terms of holding financial products (Models 2 to 6 ), the results reveal that the probability of owning a savings account (Model 2) and investing through the financial markets, either through an investment fund (Model 3), a pension scheme (Model 4) or through the purchase of shares (Model 5) and public or private fixed income assets (Model 6) increases with age.

In general, the higher the educational level, the greater the probability that the individual will own financial products. However, this positive relationship is only significant for secondary school and VT education levels and higher in the case of shares (Model 5), and university level in the case of fixed income (Model 6).

The findings show that gender only influences the contracting of savings accounts (Model 2) and investment funds (Model 4), with men being less likely to contract this type of asset.

The family unit and professional status also appear to influence the holding of financial assets. Thus, people who live with a partner are more likely to take out savings accounts (Model 2) and pension schemes (Model 3), while those who live with a partner and/or with children participate less in the fixed income markets (Model 6). Living with children also negatively influences the probability of taking out an investment fund (Model 4). Furthermore, while retirees are less likely to contract a pension scheme, self-employed workers appear to have a special interest in this type of product (Model 4), in addition to equities (Model 5).

Lastly, the higher the income level the greater the probability of using the financial markets regardless of the product. However, in the case of shares, the probability of participating in the equity markets does not increase significantly until the $€_{26,000}$ per year income bracket (Model 5), while for fixed income this threshold rises to $€ 67,500$ per year (Model 6). 


\begin{tabular}{|c|c|c|c|c|c|c|}
\hline & Model 1 & Model 2 & Model 3 & Model 4 & Model 5 & Model 6 \\
\hline Variables & Saving & $\begin{array}{l}\text { Savings } \\
\text { account }\end{array}$ & $\begin{array}{l}\text { Pension } \\
\text { scheme }\end{array}$ & $\begin{array}{r}\text { Investment } \\
\text { fund }\end{array}$ & Shares & $\begin{array}{r}\text { Fixed } \\
\text { income }\end{array}$ \\
\hline \multirow[t]{2}{*}{ Financial knowledge } & $0.142^{* * *}$ & $0.195^{* * *}$ & $0.146^{* * *}$ & $0.248^{* * *}$ & $0.303^{* * *}$ & $0.412^{* * *}$ \\
\hline & $(7.78)$ & $(9.21)$ & $(5.70)$ & $(7.42)$ & $(9.85)$ & (2.97) \\
\hline \multicolumn{7}{|l|}{ Age (Ref. 18-34) } \\
\hline \multirow[t]{2}{*}{$35-44$} & $-0.324^{* * *}$ & $0.124^{* *}$ & $0.736^{* * *}$ & $0.480^{* * *}$ & $0.358^{* * *}$ & $0.925^{* *}$ \\
\hline & $(-5.83)$ & $(2.13)$ & $(10.14)$ & $(5.58)$ & $(3.44)$ & (2.56) \\
\hline \multirow[t]{2}{*}{$45-54$} & $-0.511^{* * *}$ & 0.069 & $1.092^{* * *}$ & $0.724^{* * *}$ & $0.510^{* * *}$ & $1.200^{* * *}$ \\
\hline & $(-9.34)$ & $(1.21)$ & $(15.22)$ & $(8.55)$ & $(7.09)$ & (3.39) \\
\hline \multirow[t]{2}{*}{$55-64$} & $-0.670^{* * *}$ & $0.105^{*}$ & $1.270^{* * *}$ & $0.835^{* * *}$ & $0.609 * * *$ & $1.688^{* * *}$ \\
\hline & $(-11.79)$ & $(1.77)$ & $(17.36)$ & $(9.63)$ & $(8.18)$ & (4.94) \\
\hline \multirow[t]{2}{*}{$65-80$} & $-0.634^{* * *}$ & $0.271^{* * *}$ & $0.737^{* * *}$ & $1.132^{* * *}$ & $1.118^{* * *}$ & $2.001^{* * *}$ \\
\hline & $(-7.91)$ & $(3.36)$ & $(7.27)$ & $(9.66)$ & $(10.48)$ & (4.55) \\
\hline \multicolumn{7}{|c|}{ Education (Ref. below primary) } \\
\hline Primary and secondary & 0.061 & $0.469^{* *}$ & $0.398^{* *}$ & $0.630^{* * *}$ & 0.257 & 1.219 \\
\hline education & $(0.54)$ & $(2.92)$ & $(2.25)$ & $(2.68)$ & $(1.29)$ & $(0.85)$ \\
\hline Secondary school graduate & $0.289^{* * *}$ & $0.656^{* * *}$ & $0.610 * * *$ & $0.903^{* * *}$ & $0.633^{* * *}$ & 1.631 \\
\hline and vocational training & $(2.47)$ & $(4.03)$ & $(3.40)$ & $(3.75)$ & $(3.11)$ & (1.13) \\
\hline \multirow[t]{2}{*}{ University } & $0.570^{* * *}$ & $0.855^{* * *}$ & $0.795^{* * *}$ & $1.086^{* * *}$ & $0.845^{* * *}$ & $2.430^{*}$ \\
\hline & $(4.66)$ & $(5.16)$ & $(4.37)$ & $(4.48)$ & $(4.09)$ & (1.68) \\
\hline \multicolumn{7}{|l|}{ Gender } \\
\hline \multirow[t]{2}{*}{ Male } & -0.012 & $-0.096^{* * *}$ & 0.037 & $-0.084^{*}$ & 0.019 & 0.205 \\
\hline & $(-0.35)$ & $(-2.67)$ & $(0.93)$ & $(-1.78)$ & $(0.44)$ & (1.13) \\
\hline \multicolumn{7}{|l|}{ Family unit } \\
\hline \multirow[t]{2}{*}{ Living with a partner } & 0.006 & $0.109^{* * *}$ & $0.109^{* *}$ & 0.026 & 0.052 & $-0.456^{* *}$ \\
\hline & $(0.15)$ & $(2.52)$ & $(2.22)$ & $(0.46)$ & $(0.99)$ & $(-2.26)$ \\
\hline \multirow[t]{2}{*}{ Living with children } & $-0.229^{* * *}$ & -0.034 & 0.023 & $-0.106^{* *}$ & 0.017 & $-0.401^{*}$ \\
\hline & $(-5.75)$ & $(-0.83)$ & $(0.51)$ & $(-2.05)$ & $(0.36)$ & $(-1.94)$ \\
\hline \multicolumn{7}{|l|}{ Professional status } \\
\hline \multirow[t]{2}{*}{ Retired } & -0.014 & 0.095 & $-0.161^{* *}$ & 0.001 & -0.105 & 0.077 \\
\hline & $(-0.20)$ & $(1.35)$ & $(-2.06)$ & $(0.01)$ & $(-1.20)$ & $(0.24)$ \\
\hline \multirow[t]{2}{*}{ Self-employed } & -0.002 & 0.028 & $0.261^{* * *}$ & 0.055 & $0.284^{* * *}$ & 0.311 \\
\hline & $(-0.03)$ & $(0.51)$ & $(4.72)$ & $(0.83)$ & $(4.65)$ & (1.26) \\
\hline \multicolumn{7}{|c|}{ Income (euro) (Ref. less than 9,000) } \\
\hline \multirow[t]{2}{*}{$14,501-26,000$} & $0.445^{* * *}$ & $0.203^{* * *}$ & $0.250^{* * *}$ & $0.148^{* *}$ & 0.040 & -0.303 \\
\hline & $(10.87)$ & $(4.62)$ & $(4.93)$ & $(2.36)$ & $(0.73)$ & $(-1.15)$ \\
\hline \multirow[t]{2}{*}{$26,001-44,500$} & $0.676^{* * *}$ & $0.410^{* * *}$ & $0.487^{* * *}$ & $0.364^{* * *}$ & $0.337^{* * *}$ & 0.184 \\
\hline & (13.54) & $(8.39)$ & (8.92) & $(5.50)$ & $(5.73)$ & $(0.75)$ \\
\hline \multirow[t]{2}{*}{$44,501-67,500$} & $0.942^{* * *}$ & $0.417^{* * *}$ & $0.739^{* * *}$ & $0.411^{* * *}$ & $0.536^{* * *}$ & 0.113 \\
\hline & $(12.08)$ & $(6.22)$ & $(10.32)$ & $(4.92)$ & $(7.17)$ & $(0.36)$ \\
\hline \multirow[t]{2}{*}{ Over 67,500} & $1.105^{* * *}$ & $0.589^{* * *}$ & $0.945^{* * *}$ & $0.655^{* * *}$ & $0.875^{* * *}$ & $0.725^{* *}$ \\
\hline & $(9.60)$ & $(6.75)$ & $(10.37)$ & $(6.28)$ & $(9.53)$ & (2.27) \\
\hline Observations & 8,553 & 8,553 & 8,553 & 8,553 & 8,553 & 8,553 \\
\hline Wald & $1,209^{* * *}$ & $583^{* * *}$ & $1,021^{* * *}$ & $489^{* * *}$ & $822^{* * *}$ & $147^{* * *}$ \\
\hline
\end{tabular}

Source: Own calculations. Models 1 to 5 are probit models. Model 5 is a logistic regression model for rare events (the fixed income variable only takes a value of 1 for $1.70 \%$ of the observations). All models have been estimated including the survey weights with the exception of Model 6 . Non-standardised coefficients are shown with z-values in parentheses, Wald is the test of the joint significance of the reported coefficients of the explanatory variables, asymptotically distributed as $X^{2}$ under the null hypothesis of non-significance for the explanatory variables. The models have been estimated with a constant; however, it is not shown in the table: ${ }^{*} p<0.10$; ${ }^{*} p<0.05$; ${ }^{* *} p<0.01$ 
Table 6 shows the results of the probit models with instrumental variables. The results show that, once the potential endogeity of the financial knowledge variable is controlled for, it is no longer significant for explaining attitudes towards saving (Model 1), the holding of savings accounts (Model 2) and the contracting of pension schemes (Model 3). However, financial knowledge enhances the participation of individuals in the financial markets through the acquisition of investment fund units (Model 4), shares (Model 5) and fixed income securities (Model 6).

Further, with respect to the probit models (see Table 5), differences are observed in the significance of various demographic variables as determinants of savings and the holding of financial products. The differences found all relate to the loss of significance of some of the demographic characteristics.

Thus, with regard to the propensity for saving (Model 1), while age and living with children continue to have a significant negative impact and income continues to have a significant positive impact, education is no longer a key determinant of saving.

With regard to the holding of financial products, while the probability that individuals will have various financial assets in their portfolios increases with age, the results make it possible to refine this data to determine the age from which individuals are more likely to take out certain products. For example, in the case of savings accounts (Model 2) and fixed income (Model 6) it is 65. Additionally, while the results shown in Table 5 suggest that in general terms education increases the probability of holding various financial products, now education only seems to increase the probability of contracting a pension scheme starting at university level (Model 3) and of participating in the equity markets from secondary school level (Model 5).

In relation to the family unit, people who live with a partner remain more likely to take out a pension scheme (Model 3) and less inclined to participate in fixed income markets, as are individuals who live with children (Model 6).

In terms of professional status, being self-employed increases the probability of taking out a pension scheme (Model 3) and investing in the equity markets (Model 5). However, the being retired does not appear to influence financial decision-making, nor does the gender of the individuals, with the exception (10\% significance) of opening savings accounts (Model 2) and units in investment funds (Model 4).

Lastly, income continues to increase the probability of participating in the financial markets, but only through the acquisition and/or holding of certain assets: pension scheme (Model 3) and shares (Model 5; €26,00o per year and above).

In general, the results of the analysis seem signal the key role played by financial knowledge in making informed financial decisions, specifically in the decision to become a unitholder of an investment fund and to participate in the equity and fixed income markets. In addition, we can confirm that there is a causal relationship and its direction: financial literacy increases the probability of acquiring shares, fixed income and participating in an investment fund, not the other way around. Likew ise, the significance of other variables such as age or income in most of the financial decisions analysed stands out, while education, the characteristics of the family unit or the professional status are only decisive in specific cases. 


\begin{tabular}{|c|c|c|c|c|c|c|}
\hline & Model 1 & Model 2 & Model 3 & Model 4 & Model 5 & Model 6 \\
\hline Variables & Saving & $\begin{array}{l}\text { Savings } \\
\text { account }\end{array}$ & $\begin{array}{l}\text { Pension } \\
\text { scheme }\end{array}$ & $\begin{array}{r}\text { Investment } \\
\text { fund }\end{array}$ & Shares & $\begin{array}{r}\text { Fixed } \\
\text { income }\end{array}$ \\
\hline \multirow[t]{2}{*}{ Financial knowledge } & 0.436 & 0.557 & -0.143 & $0.736^{* *}$ & $0.353^{* * *}$ & $0.844^{*}$ \\
\hline & $(1.46)$ & $(1.61)$ & $(-0.32)$ & $(2.07)$ & (3.08) & (1.69) \\
\hline \multicolumn{7}{|l|}{ Age (Ref. 18-34) } \\
\hline \multirow[t]{2}{*}{$35-44$} & $-0.362^{* * *}$ & 0.055 & $0.758^{* * *}$ & $0.341^{*}$ & $0.250^{* * *}$ & 0.141 \\
\hline & $(-6.05)$ & $(0.59)$ & (10.70) & $(1.94)$ & $(3.22)$ & $(0.72)$ \\
\hline \multirow[t]{2}{*}{$45-54$} & $-0.569 * * *$ & -0.030 & $1.128^{* * *}$ & $0.512^{* *}$ & $0.497^{* * *}$ & 0.134 \\
\hline & $(-8.63)$ & $(-0.26)$ & $(16.12)$ & $(2.02)$ & $(6.28)$ & $(0.52)$ \\
\hline \multirow[t]{2}{*}{$55-64$} & $-0.693^{* * *}$ & 0.040 & $1.273^{* * *}$ & $0.660^{* * *}$ & $0.600^{* * *}$ & 0.391 \\
\hline & $(-12.40)$ & $(0.44)$ & $(13.11)$ & $(2.80)$ & $(7.87)$ & (1.63) \\
\hline \multirow[t]{2}{*}{$65-80$} & $-0.541 * * *$ & $0.344^{* * *}$ & $0.645^{* * *}$ & $1.126^{* * *}$ & $1.129^{* * *}$ & $0.539 * *$ \\
\hline & $(-3.66)$ & (3.63) & $(3.10)$ & $(6.95)$ & $(10.15)$ & (2.18) \\
\hline \multicolumn{7}{|l|}{ Education (Ref. below primary) } \\
\hline \multirow[t]{2}{*}{ Primary and secondary education } & -0.282 & 0.017 & 0.708 & -0.030 & 0.199 & 3.182 \\
\hline & $(-0.75)$ & $(0.03)$ & (1.44) & $(-0.05)$ & $(0.83)$ & $(0.02)$ \\
\hline \multirow{2}{*}{$\begin{array}{l}\text { Secondary school graduate and } \\
\text { vocational training }\end{array}$} & -0.205 & 0.017 & 1.048 & -0.033 & $0.550^{* *}$ & 2.986 \\
\hline & $(-0.38)$ & $(0.02)$ & $(1.57)$ & $(-0.04)$ & $(1.98)$ & $(0.02)$ \\
\hline \multirow[t]{2}{*}{ University } & 0.005 & 0.127 & $1.286^{*}$ & 0.023 & $0.752^{* * *}$ & 3.035 \\
\hline & $(0.01)$ & $(0.16)$ & $(1.74)$ & $(0.02)$ & $(2.58)$ & $(0.02)$ \\
\hline \multicolumn{7}{|l|}{ Gender } \\
\hline \multirow[t]{2}{*}{ Male } & -0.122 & $-0.228^{*}$ & 0.141 & $-0.265^{*}$ & -- & -0.237 \\
\hline & $(-1.04)$ & $(-1.76)$ & $(0.87)$ & $(-1.93)$ & & $(-1.03)$ \\
\hline \multicolumn{7}{|l|}{ Family unit } \\
\hline \multirow[t]{2}{*}{ Living with a partner } & -0.013 & 0.078 & $0.124^{* *}$ & -0.009 & 0.049 & $-0.194 * *$ \\
\hline & $(-0.30)$ & $(1.41)$ & $(2.42)$ & $(-0.15)$ & $(0.90)$ & $(-2.16)$ \\
\hline \multirow[t]{2}{*}{ Living with children } & $-0.207^{* * *}$ & -0.015 & 0.009 & -0.070 & 0.020 & $-0.159^{*}$ \\
\hline & $(-4.01)$ & $(-0.33)$ & $(0.18)$ & $(-1.16)$ & $(0.40)$ & $(-1.73)$ \\
\hline \multicolumn{7}{|l|}{ Professional status } \\
\hline \multirow[t]{2}{*}{ Retired } & -0.054 & 0.038 & -0.116 & -0.070 & -0.112 & 0.021 \\
\hline & $(-0.66)$ & $(0.42)$ & $(-1.07)$ & $(-0.69)$ & $(-1.22)$ & $(0.14)$ \\
\hline \multirow[t]{2}{*}{ Self-employed } & -0.045 & -0.028 & $0.294^{* * *}$ & -0.027 & $0.277^{* * *}$ & -0.035 \\
\hline & $(-0.63)$ & $(-0.36)$ & $(4.45)$ & $(-0.29)$ & $(4.22)$ & $(-0.22)$ \\
\hline \multicolumn{7}{|l|}{ Income (euro) (Ref. less than 9,000) } \\
\hline \multirow[t]{2}{*}{$14.501-26.000$} & $0.337^{* *}$ & 0.077 & $0.328^{* * *}$ & -0.026 & 0.025 & $-0.316^{*}$ \\
\hline & $(2.49)$ & $(0.54)$ & $(2.77)$ & $(-0.16)$ & $(0.38)$ & $(-1.78)$ \\
\hline \multirow[t]{2}{*}{$26.001-44.500$} & $0.525^{* * *}$ & 0.229 & $0.591^{* * *}$ & 0.105 & $0.315^{* *}$ & -0.284 \\
\hline & (2.78) & (1.09) & $(4.09)$ & $(0.43)$ & $(3.98)$ & $(-1.03)$ \\
\hline \multirow[t]{2}{*}{$44.501-67.500$} & $0.756^{* * *}$ & 0.205 & $0.857^{* * *}$ & 0.106 & $0.510^{* * *}$ & -0.485 \\
\hline & (3.18) & $(0.84)$ & $(5.38)$ & $(0.37)$ & (5.14) & $(-0.29)$ \\
\hline \multirow[t]{2}{*}{ Over 67.500} & $0.903^{* * *}$ & 0.353 & $1.067^{* * *}$ & 0.301 & $0.846^{* * *}$ & -0.319 \\
\hline & $(3.24)$ & $(1.25)$ & $(6.51)$ & $(0.85)$ & $(7.14)$ & $(-0.71)$ \\
\hline Observations & 8,553 & 8,553 & 8,553 & 8,553 & 8,553 & 8,553 \\
\hline Wald (i) & $1,340 * * *$ & $685^{* * * *}$ & $1,103^{* * *}$ & $735^{* * * *}$ & $812^{* * *}$ & $122^{* * * *}$ \\
\hline Wald (ii) ( $p$ value) & 0.3548 & 0.3514 & 0.5345 & 0.2720 & 0.6630 & 0.1206 \\
\hline
\end{tabular}

Source: Own calculations. Probit models with instrumental variables. Instrumented variable: financial knowledge; instruments: education relating to the economy/business (Model 1); more than 100 books at age 10 (Models 2, 3, 4 and 6) and gender (Model 5). All models have been estimated including the survey weights with the exception of Model 6 . Non-standardised coefficients are shown with $z$-values in parentheses. Wald (i) is the test of the joint significance of the reported coefficients of the explanatory variables, asymptotically distributed as $X^{2}$ under the null hypothesis of non-significance of the explanatory variables. Wald (ii) is the exogeneity test of the instrumental variable, which is asymptotically distributed as $X^{2}$ under the null hypothesis of exogeneity of the instrumental variable. The models have been estimated with a constant; however, it is not shown in the table: * $p<0.10$; ${ }^{* *} p<0.05$; ${ }^{* * *} p<0.01$ 
Existing academic literature has focused on analysing the role of financial education in financial decision-making, and there are numerous studies that assess retirement planning in different institutional contexts: The Netherlands (Alessie et al., 2011), France (Arrondel et al., 2013), Canada (Boisclair et al., 2017), Switzerland (Brown and Graf, 2013), Italy (Fornero and Monticone, 2011), United States (Lusardi and Mitchell, 2011), Germany (Bucher-Koenen and Lusardi, 2011) and Spain (Castro-González et al., 2020; Mancebón Torrubia et al., 2020). The findings indicate the importance of financial education in retirement concerns (Alessie et al., 2011) and retirement planning (Arrondel et al., 2013; Lusardi and Mitchell, 2011b; Bucher-Koenen and Lusardi, 2011), specifically increasing the probability of taking out pension schemes (Brown and Graf, 2013; Castro-González et al., 2020; Fornero and Monticone, 2011; Mancebón Torrubia et al., 2020) or other savings accounts for that purpose (Boisclair et al., 2017).

Although this study, once controlled for endogeneity, does not find that financial knowledge determines the acquisition of pension schemes, the differences with respect to the previous literature may be due to three reasons. On the one hand, some studies do not consider that the financial knowledge variable is endogenous or they assume the exogeneity of the instruments and therefore the results of these studies, such as those obtained by Castro-González et al. (2020) and Mancebón Torrubia et al. (2020) in Spain, would be in line with the results shown in Table 5. Additionally, previous studies, such as Alessie et al. (2011) assess the effect of financial knowledge on retirement planning, differentiating between basic and advanced financial knowledge. Comparing the questions in the ECF and the questions asked by Van Rooij et al. (2011), our financial knowledge variable corresponds to the basic financial knowledge variable. Alessie et al. (2011), through a GMM analysis, find that only advanced financial knowledge, not basic knowledge, influences individuals' concerns for their retirement. Lastly, not all of the studies described use the actual taking out of a pension scheme as a variable of interest, but most analyse the level of concern or retirement planning (Alessie et al., 2011; Arrondel et al., 2013; Lusardi and Mitchell, 2011b; Bucher-Koenen and Lusardi, 2011) and greater concerns or planning are not necessarily associated with taking out a pension plan.

Other studies, although less numerous, have analysed the role of financial education in the participation in equity markets (Van Rooij et al., 2011) and the likelihood of acquiring investment fund units (Müller and Weber, 2010), also finding that advanced financial knowledge has a positive impact. Mancebón Torrubia et al. (2020) analyse the impact of financial skills on saving and holding of financial assets and liabilities in Spain, concluding that in general these skills promote savings and market participation.

Academic literature looking at Spain has placed special interest in the analysis of the demographic determinants in the contracting of pension schemes (Sanchez-Campillo et al., 2016), and Castro-González et al. (2020) also include the financial knowledge of individuals as an explanatory variable. Our results are in line with the results obtained by Sanchez-Campillo et al. (2016) and Castro-González et al. (2020) in regard to demographic variables: the probability of taking out pension schemes increases with the age, educational level and income level of individuals and being self-employed. Previous studies also indicate that neither the gender of the individual 
(Sanchez-Campillo et al., 2016) or living with children (Castro-González et al., 2020) condition the probability of contracting pension schemes.

\subsection{Additional results}

Table 7 shows the results of the first stage of the probit models with instrumental variables. These results allow us to identify which demographic characteristics determine the level of financial literacy of individuals. Thus, the financial knowledge of individuals is observed to increase with age, but only up to the age of 65 . Compared to individuals aged between 18 and 34, people over 65 have a lower financial literacy level. Additionally, financial competences increase with an individual's education and income level. Lastly, living with a partner, being self-employed and being retired have a positive and significant influence on the level of financial literacy of the population. With regard to the instruments, training in areas related to economics and business, the number of books in the family home at the age of ten and being male positively influence financial literacy Our results are in line with Van Rooij et al. (2011) and Mancebón Torrubia and Ximénez-de-Embun (2020) who show how education and income levels increase financial literacy in the Netherlands and Spain, respectively. Furthermore, the results of Van Rooij et al. (2011), although they do not support the conclusion that age, marital status and professional status determine financial competences, they do show, in line with our results, the existence of a gender gap in the financial literacy of the population, as shown by Hospido et al. (2021) for Spain. 


\begin{tabular}{lrrr}
\hline Variables & Model 1 & Model 2 & Model 3 \\
\hline Economics/business education & $\begin{array}{r}\text { Financial } \\
\text { knowledge }\end{array}$ & $\begin{array}{r}\text { Financial } \\
\text { knowledge }\end{array}$ & $\begin{array}{r}\text { Financial } \\
\text { knowledge }\end{array}$ \\
\hline More than 100 books by age 10 & $\begin{array}{r}0.214^{* * *} \\
(7.44)\end{array}$ & \\
& & $0.101^{* * *}$ & \\
\hline
\end{tabular}

\begin{tabular}{|c|c|c|c|}
\hline \multicolumn{4}{|l|}{ Age (Ref. 18-34) } \\
\hline \multirow[t]{2}{*}{$35-44$} & $0.162^{* * *}$ & $0.169^{* * *}$ & $0.165^{* * *}$ \\
\hline & $(4.74)$ & $(4.96)$ & $(4.85)$ \\
\hline \multirow[t]{2}{*}{$45-54$} & $0.255^{* * *}$ & $0.262^{* * *}$ & $0.255^{* * *}$ \\
\hline & $(7.20)$ & (7.38) & (7.18) \\
\hline \multirow[t]{2}{*}{$55-64$} & $0.164^{* * *}$ & $0.173^{* * *}$ & $0.158^{* * *}$ \\
\hline & $(4.21)$ & $(4.43)$ & $(4.06)$ \\
\hline \multirow[t]{2}{*}{$65-80$} & $-0.230^{* * *}$ & $-0.225^{* * *}$ & $-0.236^{* * *}$ \\
\hline & $(-3.60)$ & $(-3.53)$ & $(-3.69)$ \\
\hline \multicolumn{4}{|l|}{ Education (Ref. below primary) } \\
\hline \multirow[t]{2}{*}{ Primary and secondary education } & $1.139^{* * *}$ & $1.135^{* * *}$ & $1.137^{* * *}$ \\
\hline & $(9.32)$ & $(9.29)$ & (9.30) \\
\hline Secondary school graduate and & $1.595^{* * *}$ & $1.593^{* * *}$ & $1.611^{* * *}$ \\
\hline vocational training & $(12.98)$ & $(12.96)$ & $(13.11)$ \\
\hline \multirow[t]{2}{*}{ University } & $1.787^{* * *}$ & $1.782^{* * *}$ & $1.817^{* * *}$ \\
\hline & $(14.50)$ & $(14.44)$ & $(14.76)$ \\
\hline \multicolumn{4}{|l|}{ Gender } \\
\hline \multirow[t]{2}{*}{ Male } & $0.375^{* * *}$ & $0.371^{* * *}$ & $0.369 * * *$ \\
\hline & $(16.50)$ & $(16.36)$ & $(16.25)$ \\
\hline \multicolumn{4}{|l|}{ Family unit } \\
\hline \multirow[t]{2}{*}{ Living with a partner } & $0.064^{* *}$ & $0.067^{* *}$ & $0.065^{* *}$ \\
\hline & $(2.14)$ & $(2.24)$ & $(2.17)$ \\
\hline \multirow[t]{2}{*}{ Living with children } & -0.047 & -0.045 & -0.047 \\
\hline & $(-1.64)$ & $(-1.55)$ & $(-1.64)$ \\
\hline \multicolumn{4}{|l|}{ Professional status } \\
\hline \multirow[t]{2}{*}{ Retired } & $0.134^{* *}$ & $0.140^{* *}$ & $0.136^{* *}$ \\
\hline & $(2.38)$ & $(2.50)$ & $(2.42)$ \\
\hline \multirow[t]{2}{*}{ Self-employed } & $0.140 * * *$ & $0.142^{* * * *}$ & $0.145^{* * *}$ \\
\hline & $(4.68)$ & $(4.74)$ & $(4.82)$ \\
\hline \multicolumn{4}{|l|}{ Income (euro) (Ref. less than 9,000) } \\
\hline \multirow[t]{2}{*}{$14,501-26,000$} & $0.305^{* *}$ & $0.306^{* * *}$ & $0.306^{* * *}$ \\
\hline & $(10.43)$ & $(10.47)$ & $(10.47)$ \\
\hline \multirow{2}{*}{$26,001-44,500$} & $0.421^{* * *}$ & $0.419 * * *$ & $0.423^{* * *}$ \\
\hline & $(14.52)$ & $(14.42)$ & $(14.53)$ \\
\hline \multirow[t]{2}{*}{$44,501-67,500$} & $0.499 * * *$ & $0.495^{* * *}$ & $0.504^{* * *}$ \\
\hline & $(13.34)$ & (13.18) & $(13.42)$ \\
\hline \multirow[t]{2}{*}{ Más de 67,500 } & $0.214^{* * *}$ & 0.525 & $0.543^{* * *}$ \\
\hline & $(7.44)$ & $(12.67)$ & $(13.16)$ \\
\hline Observations & 8,553 & 8,553 & 8,553 \\
\hline
\end{tabular}

Source: Own calculations. First stage of probit models with instrumental variables. Model 1 corresponds to the first stage of Model 1 in Table 6; Model 2 corresponds to the first stage of Models 2, 3, 4 and 6 in Table 6; Model 3 corresponds to the first stage of Model 5 in Table 6 . Non-standardised coefficients are shown with $z$-values in parentheses. The models have been estimated with a constant; however, it is not shown in the table: ${ }^{*} \mathrm{p}<0.10 ;{ }^{* *} \mathrm{p}<0.05 ;{ }^{* * *} \mathrm{p}<0.01$ 


\subsection{Robustness analysis}

In order to check whether our results are robust, alternative models have been estimated using different specifications. First, the models have been estimated using different definitions of the financial knowledge variable. Thus, three alternative variables have been estimated to measure the financial literacy of the population: i) number of questions answered correctly; ii) average score out of ten points; and iii) an index computed using the iterated principal factor method considering for each question a variable that takes the value of 1 if the question has been answered correctly and o otherwise (i.e. if it is answered incorrectly or if the individual answers "don't know/no answer"). The results of these alternative estimates do not vary, in other words, financial knowledge under the different specifications remains decisive when acquiring units in investment funds, shares or fixed income assets.

Additionally, the models whose results are shown in tables 5 and 6 have been estimated, disaggregating the education of the individuals according to Figure 7 (i.e. lower than primary; primary education; ESO; secondary education/VT courses; professional diploma/post-secondary education; higher level VT; university diploma/ degree < 240 ECTS credits; university degree > 240 ECTS credits/BA/MA; and doctorate). The results are similar, although they make it possible to more precisely identify what type of training significantly increases the probability of taking out a pension scheme or acquiring shares (the only financial products that were affected by education once endogeneity was controlled for). Thus, being in possession of a professional certificate or having completed post-secondary studies does not significantly influence the probability of taking out a pension scheme, while all other education levels do increase this probability. In contrast, the probability of participating in the equity markets increases if individuals are in possession of such a certificate, if they have completed post-secondary studies, hold a Baccalaureate diploma, a higher-level vocational training certificate or university studies. 


\section{Conclusions}

Financial culture and the quality and quantity of information available are fundamental elements in making decisions regarding savings and investment, as well as for the proper functioning of markets and the economy as a whole. The 2008 global economic crisis revealed how deficiencies in the population's financial education could lead to uninformed financial decisions. The combination of informational asymmetries in the financial markets and the lack of financial literacy in certain sectors of the population enabled complex financial products to be distributed among a population that did not understand the characteristics or risks of the products they were acquiring (Rodríguez Magdaleno et al., 2018). In recent years, significant efforts have been made to strengthen investor protection mechanisms. At the European regulatory level, the initiatives included in the new version of the Markets in Financial Instruments Directive (MiFID II) stand out, and in Spain, the financial education programmes carried out, among others, by the CNMV and the Bank of Spain since 2008 , aimed at reducing the problems caused by the lack of financial literacy.

This work provides an in-depth analysis of several aspects of the information obtained from the Financial Competences Survey in 2016 and 2017. In the first place, it provides an aggregate evaluation of the financial competences of the individuals in the sample, aiming to relate this knowledge with their different characteristics such as age, gender, education or income level, and also their predisposition to take certain financial decisions. According to the data analysis, the average score obtained in the sample in the financial knowledge evaluation is 5.99 out of 10 , with $70 \%$ of individuals showing medium or high knowledge and $25 \%$ showing low or very low knowledge. The oldest age group shows the lowest general and financial knowledge. Further, the differences between the younger age groups, which show medium and high knowledge, are minimal. A higher proportion of men $(82 \% \mathrm{com}-$ pared to $71 \%$ of women) show a medium or higher level of financial knowledge and the higher the educational level attained by the individual, the greater their financial (and general) knowledge. The data also appear to indicate the importance of acquiring the early stages of financial education in learning. There also seems to be a positive relationship between the individual's income level and their level of financial knowledge, although this relationship does not appear to be linear, in other words, the level of knowledge is relatively similar among low-income groups and the same occurs for the high-income groups. The greatest increase in knowledge appears to be in the middle income brackets.

Analysis of the individual's attitude towards saving shows that respondents generally give very high importance to saving, although almost $40 \%$ of them state that they have not saved in the past year. People who save usually opt for a very small number of financial assets, in few cases more than two. The percentage of savers appears to rise as the level of financial knowledge increases and also with the level of income. 
Second, empirical work has been carried out to contrast the role of individuals' financial knowledge in financial decision-making, which shows a positive association between financial knowledge and the propensity to save and the holding of financial products. Further, once corrected for the endogenous nature of financial education, the results show a positive impact of financial skills on the probability of participating in investment funds and of acquiring shares and fixed income assets, both public and private. The results obtained allow us to conclude that there is a causal relationship between competence and financial decisions and to establish its direction: financial knowledge increases the probability of acquiring shares, fixed income securities and in investment funds, not the reverse. The analysis also identifies the importance of age and financial income in most of the financial decisions considered in this work.

The findings of this study contribute to the academic literature analysing the role of financial literacy in financial decision-making in Spain in regard to saving and holding financial products. Further, at an international level, this study is one of the first to assess the role of financial education in this decision-making by analysing a wide range of financial products. In other words, it contributes to literature by analysing how financial knowledge and the demographic characteristics of the population influence not only the contracting of pension schemes, the acquisition of equity securities and units in investment funds, but also in taking out or acquiring other financial products that have not previously been contemplated, including savings accounts or public and private fixed income assets. The findings indicate that the role of financial competences in decision-making is not uniform but depends on the financial product being acquired and these skills are particularly influential in decisions to acquire equities and fixed income assets directly or through investment funds.

This work highlights the need for further progress in the development of suitable financial education programmes to enable the population to make informed decisions in increasingly complex financial markets. It also allows us to identify the demographic characteristics that determine the financial decisions of the population, i.e. the characteristics (gender, age, educational level, etc.) that condition the holding of a certain financial product and also the financial literacy of the population. The results can help to design better policies and programmes to enhance financial competences for different target populations.

However, the work also has certain limitations. Although the data obtained from the ECF allow us to analyse the factors that determine that individuals are more likely to save and/or acquire certain financial products, they do not allow us to establish how much they save and/or invest in financial products and services or the success of their investments. On the other hand, the ECF does not contain questions that could be considered "advanced" or "sophisticated" as used in previous empirical studies (Alessie et al., 2011; Van Rooij et al., 2011), limiting the comparison of our results with those achieved in other countries. Lastly, since the ECF is not aimed at a population that has taken part in the different financial education programmes in recent years, the effectiveness of these programmes cannot be evaluated.

In addition to the potential research topics associated with the limitations of this study, there are also other promising possible lines of research. Future research 
could look into how other variables of interest influence financial decision-making, such as an individual's risk aversion or self-control. In addition, future research could analyse and quantify the existing gaps in financial literacy, flagged in this study, such as the gender gap or others conditioned by the age or income level of the individuals, among other socio-economic variables. Lastly, given that the ECF assesses the extent to which individuals have knowledge of various financial products, it would be interesting to analyse in the subsample of individuals with knowledge of the existence and operation of various financial products which are the determinants that ultimately influence their contracting. 



\section{References}

Alessie, R., Van Rooij, M. \& Lusardi, A. (2011). "Financial literacy and retirement preparation in the Netherlands". Journal of Pension Economics \& Finance, Vol. 10, No. 4, pp. 527-545.

Arrondel, L., Debbich, M. \& Savignac, F. (2013). "Financial literacy and financial planning in France". Numeracy, Vol. 6, No. 2.

Bartlett, M. (1937). "The statistical conception of mental factors". British Journal of Psychology, Vol. 28, pp. 97-104.

Boisclair, D., Lusardi, A. \& Michaud, P.C. (2017). "Financial literacy and retirement planning in Canada”. Journal of Pension Economics \& Finance, Vol. 16, No. 3, pp. 277296.

Brown, M. \& Graf, R. (2013). "Financial literacy and retirement planning in Switzerland". Numeracy, Vol. 6, No. 2.

Bucher-Koenen, T. \& Lusardi, A. (2011). "Financial literacy and retirement planning in Germany". Journal of Pension Economics \& Finance, Vol. 10, No. 4, pp. 565-584.

Castro-Gonzalez, S., Rey-Ares, L., Fernandez-Lopez, S. \& Daoudi, D. (2020). "The effect of self-control upon participation in voluntary pension schemes". Economics and Sociology, Vol. 13, pp. 11-23.

Fornero, E. \& Monticone, C. (2011). "Financial literacy and pension plan participation in Italy". Journal of Pension Economics \& Finance, Vol. 10, No. 4, pp. 547-564.

Hospido, L., Izquierdo, S. \& Machelett, M. (2021). "Diferencias de género en competencias financieras”. Boletín Económico, Quarter 1, Banco de España.

Lusardi, A. \& Mitchell, O.S. (2011a). "Financial literacy and planning; Implications for retirement wellbeing", in A. Lusardi \& O.S. Mitchell (eds). Financial Literacy. Implications for retirement security and the financial marketplace, Oxford University Press, pp. 17-39.

Lusardi, A. \& Mitchell, O.S. (201 1b). "Financial literacy and retirement planning in the United States”. Journal of Pension Economics \& Finance, Vol. 10, No. 4, pp. 509-525.

Mancebón Torrubia, M.J. \& Ximénez-de-Embún, D.P. (2020). "Habilidades financieras de la población española adulta: diagnóstico y determinantes". Papeles de Economía Española, Vol. 166, pp. 166-184 
Mancebón Torrubia, M.J., Ximénez-de-Embún, D.P. \& Villar-Aldonza, A. (2020). “Habilidades financieras y hábitos financieros saludables: un análisis a partir de la Encuesta de Competencias Financieras". Cuadernos de Información Económica, Vol. 275, pp. 55-69.

Müller, S. \& Weber, M. (2010). "Financial literacy and mutual fund investments: Who buys actively managed funds?". Schmalenbach Business Review, Vol. 62, pp. 126-153

Rodríguez Magdaleno, R., Martínez García, I. \& Gómez Ansón, S. (2018). "Financial crisis and consumers: Breaking down barriers to build up new ones?", in S. De Vries, E. Ioriatti, P. Guarda \& E. Pulice (eds.). EU citizen' economic rights in action. Rethinking legal and factual barriers in the internal market, Edward Elgar Publishing, pp. 17-39.

Sanchez-Campillo, J., Moreno-Herrero, D. \& Rodríguez-Martín, J.A. (2016). "Efectos de la educación en el nivel de las contribuciones a los planes privados de pensiones de las familias en España". Innovar, Vol. 26, No. 62, pp. 95-112.

Van Rooij, M., Lusardi, A. \& Alessie, R. (2011). "Financial literacy and stock market participation”. Journal of Financial Economics, Vol. 101, No. 2, pp. 449-472 


\section{Appendix}

\section{Factor scores for questions on financial competences}

Image that five siblings have $€ 1,000$ to share and they will have to wait one year to get their share and that inflation in that year was $1 \%$. Within Correct $\quad 0.3907$ a year they will be able to buy: i) more than they could buy today with DK/DA $\quad-0.5173$ their share of the money, ii) the same amount, iii) less than they could buy today, or iv) it depends on the kinds of things they want to buy

If you lend $€ 25$ to a friend one night and the friend returns $€ 25$ to you the following day, what interest have you charged on the loan?

\begin{tabular}{rr} 
Correct & 0.2583 \\
\hline DK/DA & -0.2625 \\
\hline Correct & 0.5261 \\
\hline DK/DA & -0.6239
\end{tabular}

Suppose you deposit $€ 100$ in a savings account with a fixed interest rate DK/DA $\quad-0.6239$ you make no other deposit in this account and do not withdraw money, how much money will there be in the account at the end of the first year, once interest has been paid?

Once again, if you make no deposit or withdraw, once the interest payment has been paid to you, how much money will there be in the account after five years: over $€ 110$, exactly $€ 110$, less than $€ 110$ or it is impossible to say it with the information given?

\begin{tabular}{|c|c|c|}
\hline \multirow{2}{*}{$\begin{array}{l}\text { True or false: An investment with a high return is also likely to be high } \\
\text { risk. }\end{array}$} & Correct & 0.5618 \\
\hline & DK/DA & -0.6110 \\
\hline \multirow{2}{*}{$\begin{array}{l}\text { True or false: Generally, it is possible to reduce the risk of investing on } \\
\text { the stock exchange by buying a wide variety of shares. }\end{array}$} & Correct & 0.4807 \\
\hline & DK/DA & -0.5729 \\
\hline \multirow{2}{*}{$\begin{array}{l}\text { True or false: A } 15 \text {-year mortgage typically requires higher monthly } \\
\text { payments than a } 30 \text {-year mortgage, but the total interest paid over the } \\
\text { duration of the loan will be lower. }\end{array}$} & Correct & 0.3523 \\
\hline & DK/DA & -0.4858 \\
\hline \multirow{2}{*}{$\begin{array}{l}\text { Who could benefit the most from an unexpected increase in inflation: i) } \\
\text { a household that has a fixed interest rate mortgage, ii) a bank that has } \\
\text { granted a fixed income rate mortgage, or iii) a household that lives from } \\
\text { fixed income asset returns? }\end{array}$} & Correct & 0.3166 \\
\hline & DK/DA & -0.4513 \\
\hline
\end{tabular}

Source: Own calculations. 
